\title{
Electrical Properties of Mid-Ocean Ridge Basalt and Implications for the Structure of the Upper Oceanic Crust in Hole 504B
}

\author{
PHILIPPE A. PEzard \\ Borehole Research Group of the Lamont-Doherty Geological Observatory \\ and Department of Geological Sciences, Columbia University, Palisades, New York
}

\begin{abstract}
The electrical resistivity, porosity, and cation exchange capacity (CEC) of mid-ocean ridge basalt (MORB) samples from Deep Sea Drilling Project hole 504B have been measured in the laboratory. The presence of chlorites, zeolites and particularly smectites as alteration products of MORB is reflected by high values of CEC, with high and uniform CEC values in the massive units of layers $2 \mathrm{~A}$ and $2 \mathrm{~B}$, and even higher values in the pillows. The porosity and the "intrinsic" formation factor are related, in the massive units, by an inverse power law similar to Archie's formula, with $m=1.0$ and $a=10.0$. Such a low $m$ value equates to current conduction in cracks and microcracks present at mineral scale throughout the rock. During leg 111 of the Ocean Drilling Program, the Joides Resolution D.V. returned in the equatorial Pacific to deepen hole 504B and to perform a series of downhole experiments. A continuous electrical resistivity profile permitted to discriminate the large-scale seismic layers of the upper oceanic crust and to isolate individual lithologic units. In the extrusive part of the crust, the massive flows (10-m-thick or more) are found to constitute permeability barriers and subsequently, to constrain fluid circulation. Within layer $2 \mathrm{~A}$, the massive flows of unit $2 \mathrm{D}$ are associated with the underpressured aquifer located underneath, within Unit 3 . In layer $2 \mathrm{~B}$, unit 27 is the boundary between low-temperature, seawater alteration facies of basalt, and highertemperature alteration phases. This relationship between morphology, hydrological regime, and therefore alteration of the basaltic basement is proposed to be related to the accretion process of the upper oceanic crust. The porosity estimate derived from in situ measurements of electrical resistivity is reduced when accounting for surface conduction, with high values computed in layer $2 \mathrm{~A}$ only. A permeability profile computed on the basis of in situ resistivity measurements reproduces those obtained in situ from packer experiments, and therefore provides a key to the low-permeability high-"apparent"-porosity paradox obtained in the past.
\end{abstract}

\section{INTRODUCTION}

The physical structure of oceanic plates has been a subject of widespread interest in geosciences over the past 50 years, particularly since the advent of plate tectonics. Several Deep Sea Drilling Project (DSDP) and Ocean Drilling Program (ODP) expeditions [Anderson, et al., 1985a; Donnelly, et al., 1979], seismic and electromagnetic remote sensing [Houtz and Ewing, 1976; Luyendyk and Macdonald, 1977; Francheteau, 1983; Cox, 1971; Young and Cox, 1981; Cox et al., 1986] and direct exploration of mid-ocean ridges with submersibles [ARCYANA, 1975; Ballard et al., 1975; Macdonald, 1983] have permitted the construction of a substantial data base on the upper structure of oceanic plates. The comparison of oceanic heat-flow measurements to theoretical cooling plate models [Sclater and Francheteau, 1970; Anderson and Hobart, 1976], and the discovery of black smokers [Corliss et al., 1979; Spiess et al., 1980] have demonstrated that the oceanic crust is a porous medium permeated by convecting hydrothermal fluids [Lister, 1972; Williams et al., 1974; Fehn et al., 1983]. As evolved seawater circulates and reacts with igneous phases of the

Copyright 1990 by the American Geophysical Union.

Paper Number 90JB00268.

0148-0227/90/90JB-00268\$05.00 basaltic crust to produce alteration minerals, it rapidly contributes to the plugging of the existing pore space, partly sealing the crust. In turn, this gradual sealing prevents fluid circulation and reduces the alteration rate.

The oceanic crust consequently operates as a giant buffer to worldwide ocean water keeping, for instance, the salinity constant over hundreds of million years by means of this hydrochemical regulation [Sleep and Wolery, 1978; Edmond et al., 1979]. Thus the circulation of seawater in the pore spaces of the crust stands out as one of the dominant processes in the aging of oceanic plates. Understanding the evolution of this complex filtering process, with the description of the porosity and permeability structure of the upper crust from boreholes as natural in situ laboratories, is therefore of prime interest in the context of plate tectonics and the study of the earth as a regulated system. This paper describes an analysis of midocean ridge basalt (MORB) physical properties both in situ with borehole experiments and in the laboratory on core samples. Since two very different volumes of rock are investigated by such types of measurements [Brace, 1984], the results of these analyses cannot be directly compared. As a consequence, each data set is used to constrain the other, within the framework of its own limitations.

\section{Porosity and permeability of the upper oceanic crust}

Unlike bulk density, acoustic velocity, or electrical 
resistivity, porosity and permeability of the basaltic crust are not at present directly measurable in situ with geophysical logs. Whereas porosity is estimated routinely from resistivity [Archie, 1942], nuclear [Ellis, 1987], or acoustic experiments in sedimentary formations [Wyllie et al., 1958], the very different structure of the pore space of crystalline rocks, or the presence as traces of elements such as gadolinium or boron (with large capture cross sections to neutrons), has prevented to date the development of an accurate method for deriving in situ porosity estimates. Since permeability is governed not only by porosity but also by size, shape, tortuosity, arrangement of the pore space (all difficult to evaluate), and other parameters such as pore pressure or ambient stresses, there has been no precise and unique derivation of permeability from geophysical logs.

Anderson and Zoback [1982], Hickman et al. [1984], Anderson et al. [1985c] and Becker [1989] have shown that in situ measurements of permeability made with an hydraulic packer are suitable for studying the variations with depth, and the modifications with age, of this filtering system. In hole 504B, the comparison of these direct permeability measurements with porosity profiles derived from Archie's law using long-spacing measurements of electrical resistivity [Francis, 1982; Becker, 1985], has (1) confirmed the vertical zonation of the oceanic crust known from studies on ophiolites [Gass and Smewing, 1973; Kidd, 1977], (2) emphasized the overall decrease in porosity and permeability of the crust with increasing depth [Becker, 1985], and (3) outlined the limitations of this resistivityporosity-permeability transform in sections thought to be porous (with an "apparent" porosity up to $7.0 \%$ in hole $504 \mathrm{~B}$, at the base of layer $2 \mathrm{~B}$ ), but measured to be poorly permeable (of the order of $10^{-17} \mathrm{~m}^{2}$, about 0.01 millidarcy [Becker, 1989]).

\section{Electrical properties of MORB}

The extreme sensitivity of electrical properties to a large number of parameters makes electromagnetic methods both a complex and a powerful technique to study large and small scale structures of rock formations. Although the known electrical properties of rocks and minerals have been observed to vary over 24 orders of magnitude in the Earth [Parkhomenko, 1967; Olhoeft, 1981], the measurements made so far in the oceanic crust have covered less than 6 orders of magnitude. In situ measurements of electrical resistivity respond directly to conductivity changes in the rock surrounding the borehole. The presence of vesicular pores, cracks and microcracks, either filled with fluids, or plugged with precipitated conductive alteration minerals such as chlorites, zeolites, and smectites, create a path for current flow. In basalts, the electrical conduction is a combination of electrolytic mechanisms for the fluid-filled fractures, and surface-mediated ion transport for conductive alteration minerals. Since an order of magnitude separates the

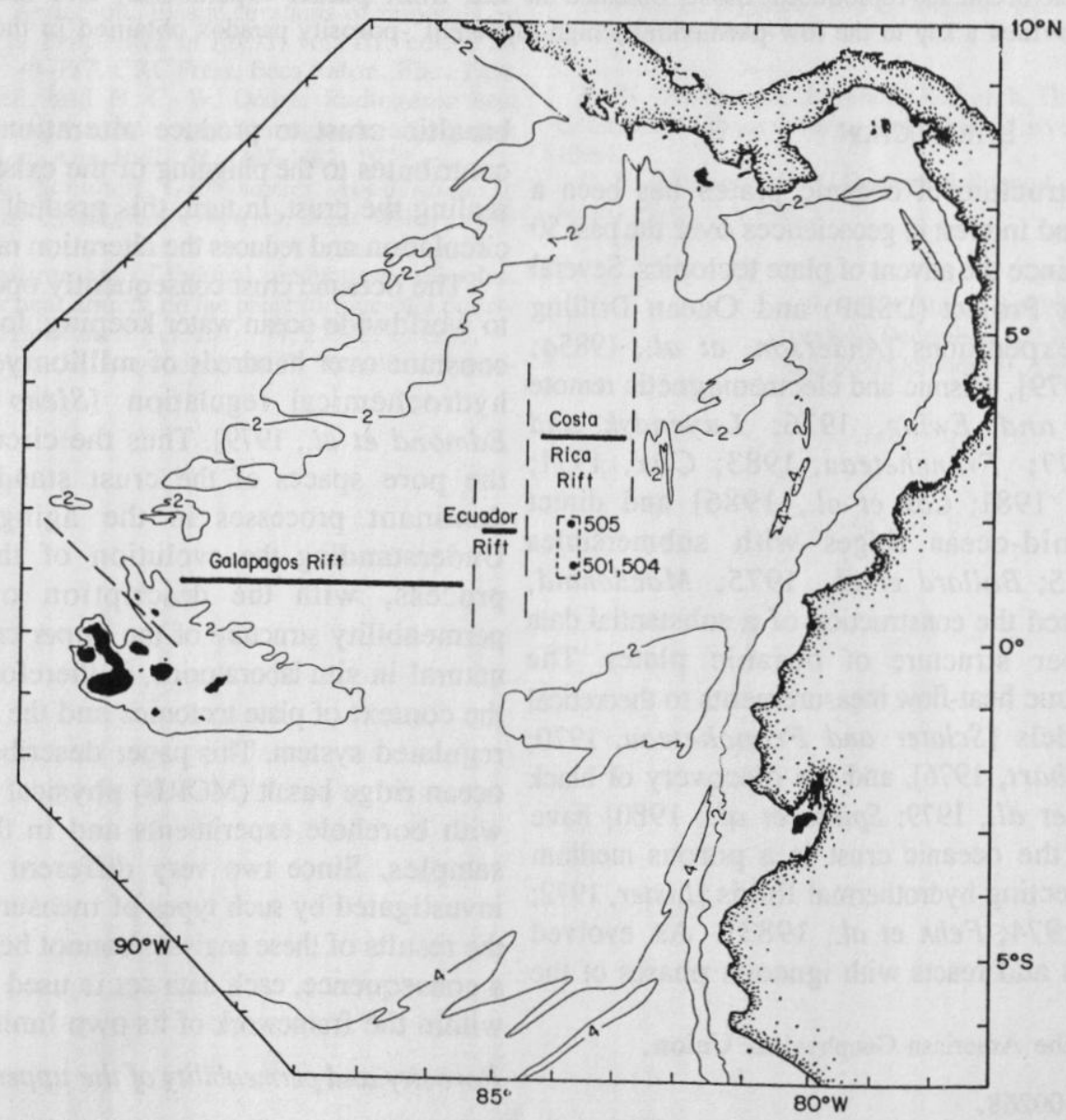

Fig. 1. Location of site 504 on the south flank of the Costa Rica rift, Panama basin. Bathymetry from Lonsdale and Klitgord [1978]. Contour interval $=2000 \mathrm{~m}$. 
resistivity of alteration minerals (a few $\Omega . m$ in situ), to that of seawater (about $0.2 \Omega \cdot \mathrm{m}$ at $25^{\circ} \mathrm{C}$ ), the measurements of electrical resistivity are sensitive to the progressive sealing of the oceanic crust with basalt alteration products.

In this paper, a series of core measurements is reported in order to evaluate whether the presence of alteration minerals in the oceanic crust might constitute a significant contribution to current conduction during resistivity logging. If present, such a contribution would cause estimates of porosity based on Archie's law to be too high. The results of this analysis are (1) compared with previous studies of MORB and other crystalline rocks [Olhoeft, 1977; Ucok, 1979; Drury and Hyndman, 1979; Pape et al., 1985; Flovenz et al., 1985; Broglia and Moos, 1988], (2) used as a basis to analyze the data recorded in situ, adapting to logging data the approach used by Becker [1985] with long-spacing resistivity measurements, then (3) discussed in relation to the porosity-permeability anomaly described earlier.

\section{ELBCTRICAL EXPERIMENTS IN DSDP H OLE 504B}

On ODP leg 111, the Joides Resolution drillship returned to DSDP site 504, in the eastern equatorial Pacific (Figure 1). Hole 504B, the deepest borehole yet drilled into the oceanic crust, was reentered to study the crustal structure and the hydrothermal processes at this well-sedimented reference site [Becker, et al., 1989]. The drillhole is located about $200 \mathrm{~km}$ to the south of the Costa Rica rift, in $5.9 \mathrm{Ma}$ oceanic crust. It was cored and logged by four DSDP legs $(69,70,83$, and 92$)$ and deepened $213.3 \mathrm{~m}$ into the sheeted dikes of layer $2 \mathrm{C}$ during ODP leg 111 (Figure 2). It reaches

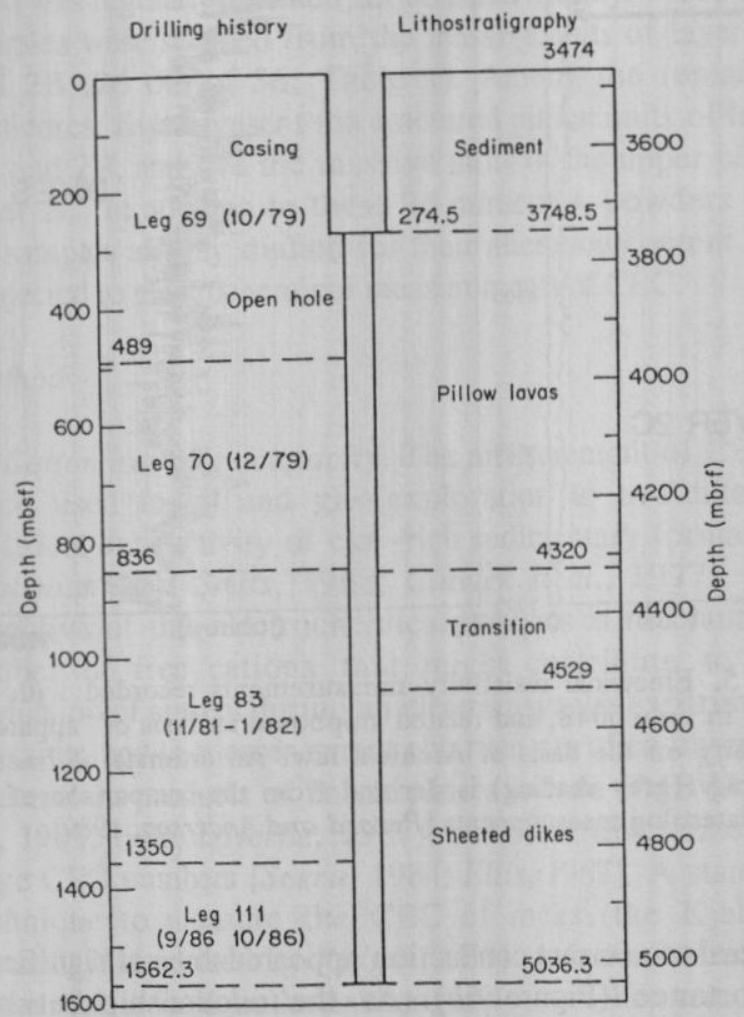

Fig. 2. Schematic of hole 504B drilling history and lithostratigraphy through leg 111 [after Becker et al.,1989]. now a total depth of $1562.3 \mathrm{~m}$ below seafloor (mbsf), penetrating $274.5 \mathrm{~m}$ of sediments and $1287.8 \mathrm{~m}$ of intensely fractured basaltic basement [Adamson, 1985]. Leg 111 also provided the opportunity to conduct an extensive suite of in situ experiments, including permeability measurements in the sheeted dikes complex, and the recording of continuous electrical resistivity data in basement with the Schlumberger Dual Laterolog tool (DLL). An "apparent" porosity profile was computed on board the drillship from the DLL data in a similar way to that used during DSDP leg 83 from a largescale resistivity experiment [Becker, 1985]. The comparison of this porosity profile with in situ permeability measurements (Figure 3) led to the low-permeability high"apparent"-porosity paradox described by Becker [1985], as it seemed contradictory that low-"apparent"-porosity dikes from layer $2 \mathrm{C}$ (below $2.0 \%$ ) and high-"apparent"-porosity pillows from layer $2 \mathrm{~B}$ (above $8.0 \%$ ) have the same permeability.

A schematic of the DLL sonde run during leg 111 is given in Figure 4, with an idealized sketch of the current flow within the rock. The principle of the DLL is to measure the intensity of a variable current focused in a 60 $\mathrm{cm}$-thick cylindrical beam. This current flows from a downhole electrode to a remote return under a fixed difference of potential [Serra, 1984; Ellis, 1987; Shipboard Scientific Party, 1988]. The intensity of the measured current is inversely proportional to the formation resistivity. This sensor is accurate at high resistivity values (error under $1.0 \%$ up to $40000 \Omega$.m) and provides two measurements of

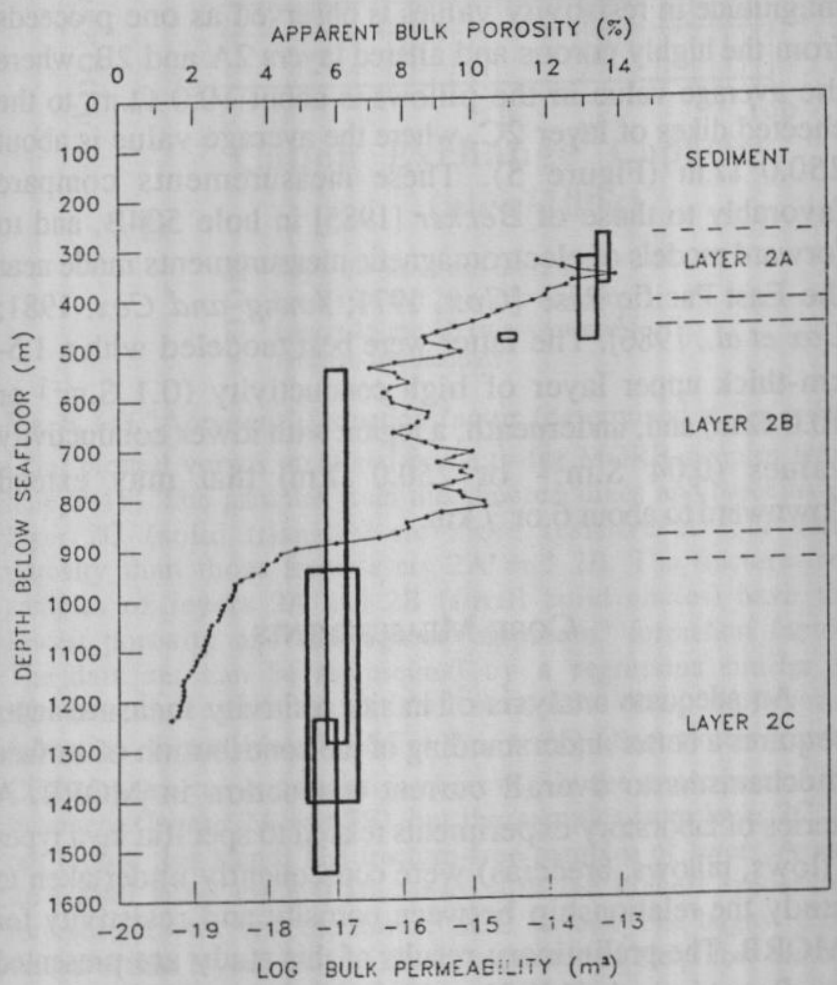

Fig. 3. Measured bulk permeabilities (elongate vertical rectangles) and "apparent" bulk porosities versus depth in hole 504B. The vertical extent of the rectangle represents the depth interval over which average permeabilities were measured. The horizontal extent represents the range of estimated errors in the permeability determination [after Becker et al.,1989]. 


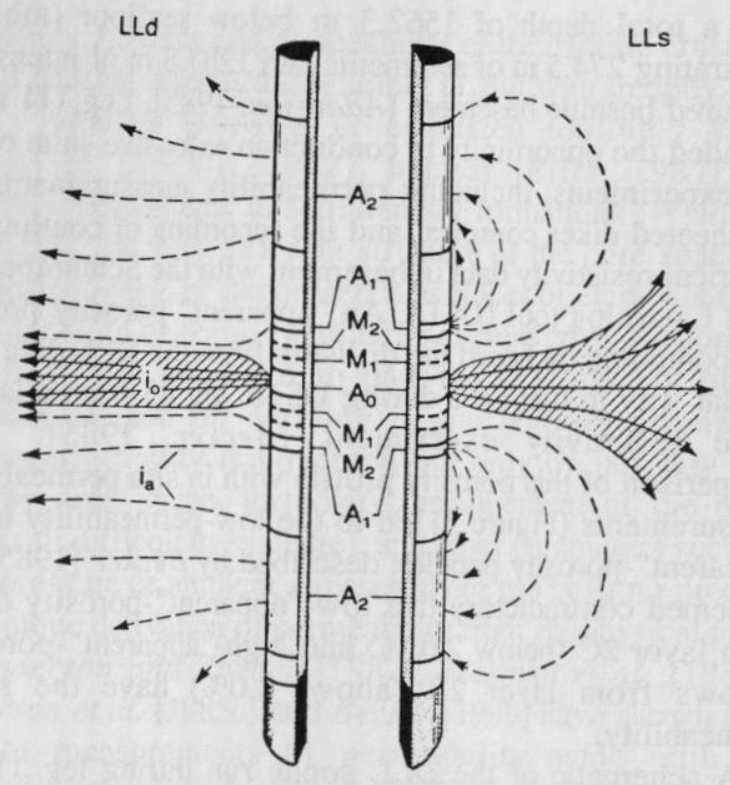

Fig. 4. Sketch of the Dual Laterolog sonde (DLL), and idealized current flow into the rock (with the "shallow" current to the right (LLs), and the "deep" current to the left (LLd)). The electrode arrangement is described in the middle of the split downhole sensor.

resistivity refered to as "deep" and "shallow" due to their respective horizontal penetration into the rock. On ODP leg 111 , the measurements made with the DLL covered depths from 5003 to $3758 \mathrm{~m}$ (or 1529 to $284 \mathrm{mbsf}$ ), with a datum acquired every $15.2 \mathrm{~cm}$. An increase of about two orders of magnitude in resistivity values is observed as one proceeds from the highly porous and altered layers $2 \mathrm{~A}$ and $2 \mathrm{~B}$, where the average value in the pillows is about $10.0 \Omega . \mathrm{m}$, to the sheeted dikes of layer $2 \mathrm{C}$, where the average value is about

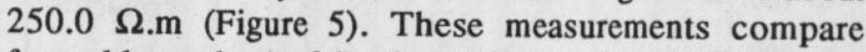
favorably to those of Becker [1985] in hole 504B, and to forward models of electromagnetic measurements made near the East Pacific Rise [Cox, 1971; Young and Cox, 1981; Cox et al., 1986]. The latter were best modeled with a 1.5km-thick upper layer of high conductivity $\left(0.1 \mathrm{~S}^{-1} \mathrm{~m}^{-1}\right.$ or $10.0 \Omega . \mathrm{m})$ and, underneath, a region with lower conductivity values $\left(0.04 \mathrm{~S} . \mathrm{m}^{-1}\right.$ or $\left.250.0 \Omega . \mathrm{m}\right)$ that may extend downward to about 6 or $7 \mathrm{~km}$.

\section{Core Measurements}

An adequate analysis of in situ resitivity measurements requires a better understanding of the contribution of surface mechanisms to overall current conduction in MORB. A series of laboratory experiments related to specific lava types (flows, pillows, breccias) were consequently undertaken to study the relationship between porosity and resistivity for MORB. The preliminary results of this study are presented by Pezard et al. [1989], with only one measurement of resistivity for each sample (at seawater salinity). This single measurement was used to compute an "apparent" formation factor (defined as the resistivity of the fluid-saturated rock divided by the resistivity of the fluid (with $F F=$ $\left[R_{o} / R_{w}\right]$; Figure $6 a$ ), while the contribution of alteration

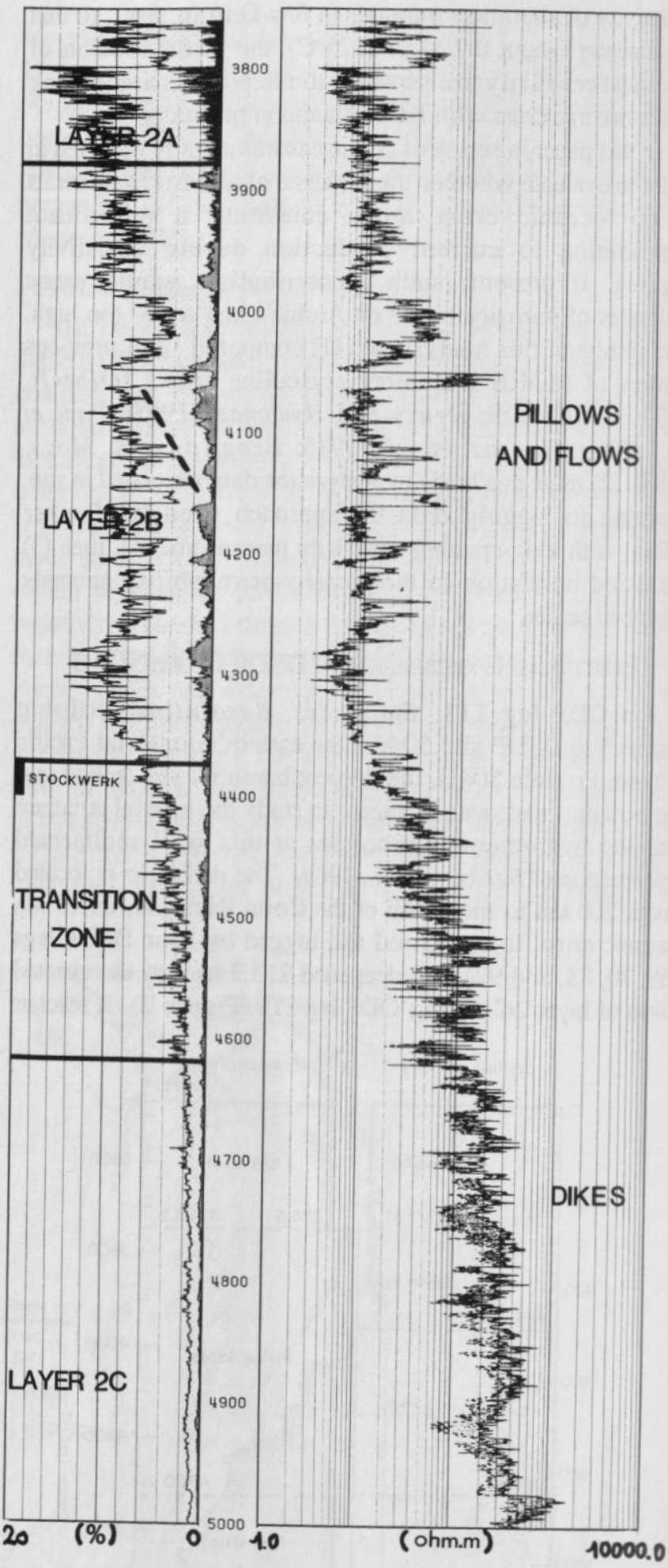

Fig. 5. Electrical resistivity measurements recorded with the DLL in hole 504B, and related shipboard analysis of "apparent" porosity on the basis of Archie's law. An estimate of fracture porosity (grey shading) is derived from the comparison of the two laterolog measurements [Pezard and Anderson, 1989].

minerals to current conduction appeared to be of significant importance (Figure $6 b$ ). As the relationship between resistivity and formation factor is not linear when surface conduction is present, the computation of the "intrinsic" formation factor [Worthington, 1985] from measurements 
made at different saturating-fluid salinities was needed to analyze the logging data. The "intrinsic" formation factor of a rock sample is computed at high saturating-fluid salinity, where the surface conduction is negligible and the formation factor is indeed linearly related to resistivity.

A total of 36 basalt minicores were sampled from the DSDP/ODP core repository to measure porosity, electrical resistivity (at five different saturating-fluid salinities), and cation exchange capacity (CEC). Prior to this study, the samples were kept dry and refrigerated for an average period of four years in the DSDP/ODP core repository. Such a handling procedure is naturally not the preferred one (1) due to the importance of the fluid phase for resistivity measurements and (2) because drying certainly damaged the mineralogical assemblage present in situ. In recent studies of the electrical properties of gabbros from the Indian Ocean (ODP leg 118), and volcanic rocks from the Bonin arc (ODP leg 126), the samples were cut on board ship prior to desaturation and preserved individually in seawater. This technique is certainly preferable to several years of dry storage, but was unfortunately not used in this case. The importance of hole 504B in the context of ocean drilling nevertheless justified te present analysis. In an attempt to compensate for the desaturation of the samples, extreme care was taken to resaturate them. Distilled water was used to eliminate the salts deposited in the pore space while drying in storage. The samples were dried again for dry-weight measurements, then saturated with $\mathrm{NaCl}$ solutions under near-vacuum conditions. During the course of the measurements, the samples were stored in a $\mathrm{NaCl}$ solution (corresponding to the desired fluid conductivity), and the bath fluid was regularly checked for constant salinity. Most of the samples were selected from the massive units of layers $2 \mathrm{~A}$ and $2 \mathrm{~B}$ ( 26 out of 36 ; Table 1$)$. Among the remaining minicores, five represent the fractured pillow units of layers $2 \mathrm{~A}$ and $2 \mathrm{~B}$, and five the massive units of the upper part of layer $2 \mathrm{C}$. In addition to these 36 minicores, powders from 29 samples already studied for their alteration content were subjected to electrochemical measurements of CEC.

\section{Method}

Cation exchange capacity. The measurement of CEC is often used in oil and gas exploration to evaluate the electrical conductivity of clay-rich sedimentary formations [Waxman and Smits, 1968; Clavier et al., 1977]. The objective of this electrochemical analysis is to count the number of free cations that might contribute to the conduction of current during an electromagnetic experiment. Smectites, and to a lesser extent chlorites, are often observed as alteration products of basalt phases in hole 504B [Alt et al., 1985, 1986; Laverne, 1987], and are characterized by large CEC numbers [Serra, 1984; Ellis, 1987]. A standard technique to measure the CEC of rocks (the Kjeldahl method) is described by Ridge [1983]. A cation not native to the rock is fixed on the exchangeable sites, then removed, and its quantity measured.

For analysis, each of the 65 samples was crushed, and a quantity of $1-2 \mathrm{~g}$ was taken after thorough mixing. The
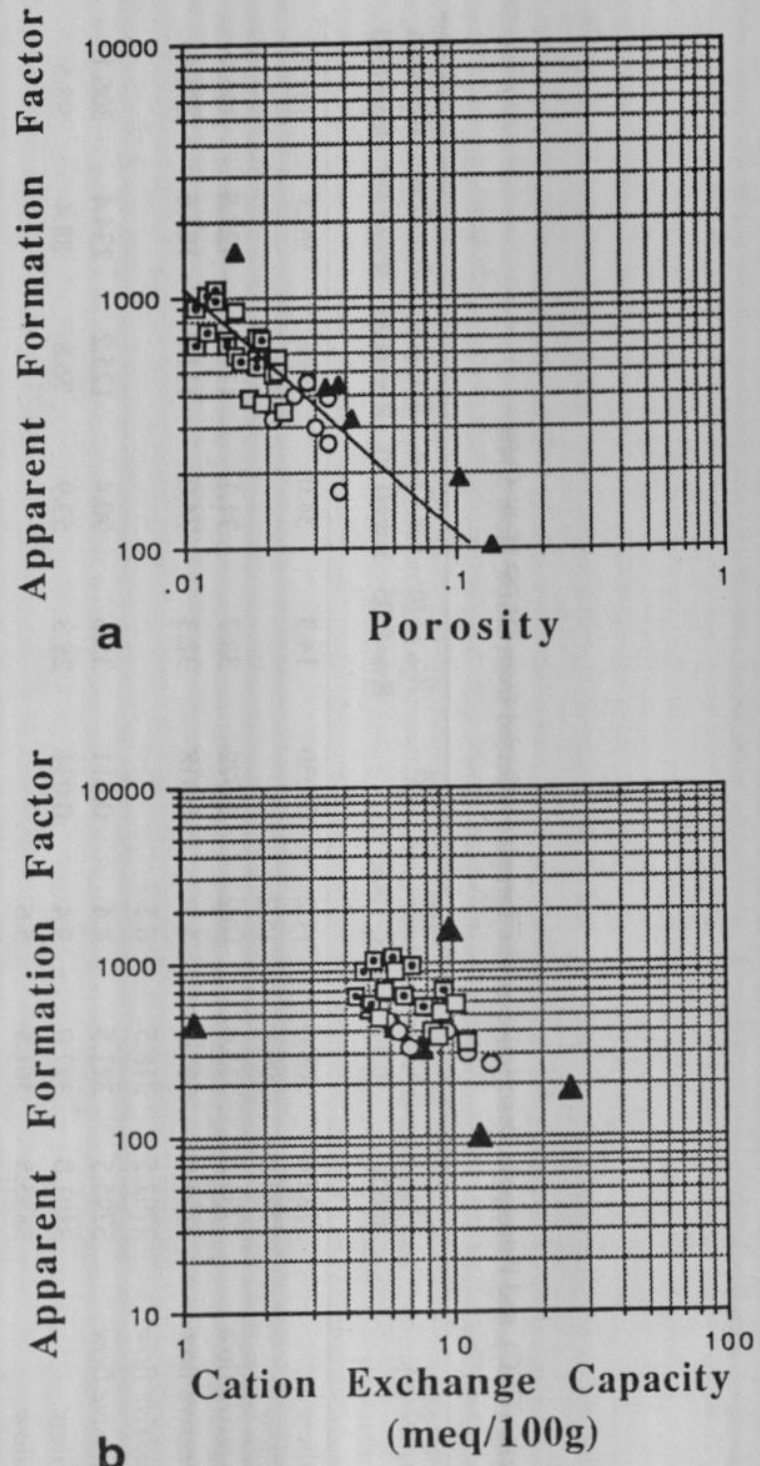

A Layer $2 \mathrm{C}$ (dikes and breccias)
Layers $2 \mathrm{~A}$ and $2 \mathrm{~B}$ (pillow units)
- Layers $2 \mathrm{~A}$ and $2 \mathrm{~B}$ (massive units)
- Fracture-free samples

Fig. 6. (a) "Apparent" formation factor (determined at $\mathrm{R}_{\mathrm{W}}=0.2$ $\Omega$.m) plotted versus measured porosity for MORB samples from hole 504B. The samples from the sheeted dikes and breccias of layer $2 \mathrm{C}$ (solid triangles) are more resistive at equivalent porosity than those from layers $2 \mathrm{~A}$ and $2 \mathrm{~B}$. The fracture-free samples of layers $2 \mathrm{~A}$ and $2 \mathrm{~B}$ (small solid circles) have the lowest porosity and the highest "apparent" formation factor. The data set can be represented by a regression similar to Archie's law with $a=9.1$ and $m=1.05$. (b) "Apparent" formation factor (determined at $R_{\mathrm{W}}=0.2 \Omega \mathrm{m}$ ) plotted versus CEC. An inverse correlation is observed in the upper part of the basement (layers $2 \mathrm{~A}$ and $2 \mathrm{~B}$ ), but the samples from layer $2 \mathrm{C}$ do not follow this trend. The fracture-free samples of layer $2 \mathrm{~A}$ and 2B (small solid circles) are those with the highest "apparent" formation factor and the lowest CEC values. The largest CEC values within layers $2 \mathrm{~A}$ and $2 \mathrm{~B}$ are recorded in the pillow units .

samples were made water-wet to disperse zeolites and clays, then washed and centrifuged three times with ammonium acetate in order to locate an ammonium ion at each of the potential exchangeable sites. Once diluted with water and 
ethyl alcohol, sodium hydroxide was used to replace the ammonium ions. Finally, the ammonium ions were condensed in a reducing environment, collected as ammonia, and titrated in the Kjeldahl unit with hydrochloric acid. Laboratory tests on standards indicate that this technique has a resolution of $0.1 \mathrm{meq} / 100 \mathrm{~g}$ and an accuracy of the order of $0.5 \mathrm{meq} / 100 \mathrm{~g}$. The results are expressed in milliequivalents per $100 \mathrm{~g}$ of wet rock $(\mathrm{meq} / 100 \mathrm{~g})$, or in milliequivalents per liter (meq/L), if converted into CEC per unit pore volume (referred as $Q_{\nu}$ in Clavier et al. [1977]).

Porosity and electrical resistivity. Porosity and electrical resistivity were measured on the 36 minicores of basalt, each $25 \mathrm{~mm}$ in diameter and $13-23 \mathrm{~mm}$ long. The samples were cut from the working half of the cores, in a direction perpendicular to the axis of the original core. The porosity was determined by standard immersion method. The core plugs were saturated with distilled water in an evacuation cell for 48 hours. For dry weights, the plugs were dried at $65^{\circ} \mathrm{C}$ for 12 hours. Since the instrument precision is $\pm 0.0001 \mathrm{~g}$ and the reproducibility is $\pm 0.0005 \mathrm{~g}$, an experimental error of about 0.001 ( $0.1 \%$ in porosity units) is inherent to this technique for porosity measurements. The electrical resistivity of the 36 samples was measured at $23.5^{\circ} \mathrm{C}$ and atmospheric pressure, after they had been saturated with a $\mathrm{NaCl}$ solution of appropriate salinity. In all, five consecutive sets of measurements were made at saturating-fluid salinities of $0.052,0.105,0.195,1.02$, and $7.93 \Omega$.m. Once the first set made at a salinity equivalent to that of seawater $(0.195 \Omega . \mathrm{m})$, the saturating-fluid was modified for each subsequent test by putting the samples in a bath of chosen salinity, and exposing them to a constant temperature of $65^{\circ} \mathrm{C}$. The bath fluid was replaced until the salinity stabilized. This was always observed to occur within 36 hours.

A $10 \mathrm{mV}, 50 \mathrm{~Hz}$ signal was applied to the samples with a Wayne-Kerr bridge to make measurements of electrical resistivity at a frequency similar to those used in situ by the Dual Laterolog. The resistivity was measured by attaching a stainless steel electrode to each end of the core plugs [Brace et al., 1965; Rai and Manghnani, 1981]. A teflon wrapping was applied to the cylinder surfaces in order to prevent desaturation during the course of the measurements. In spite of a lower accuracy, the use of a two-electrode set up was preferred to a four-electrode system due to the great difficulty of obtaining reproducible results with the latter. Because the samples were of different lengths, they would tend to damage the rubber jacket and induce current leaks on the outer surface of the minicore. In this case, the measurements were meaningless (Figure 7). Considering that the four-electrode device was increasing the difficulty of the experiment by at least an order of magnitude and that the four-electrode results were similar to those obtained with the two electrode-configuration (Figure 7), it was decided to abandon the unreliable four-electrode device. A series of measurements made on a few samples at six different frequencies (Table 2) shows a small decrease of the resistivity with increasing frequency, which proves that the interfacial impedance of the electrodes is small at $50 \mathrm{~Hz}$. The

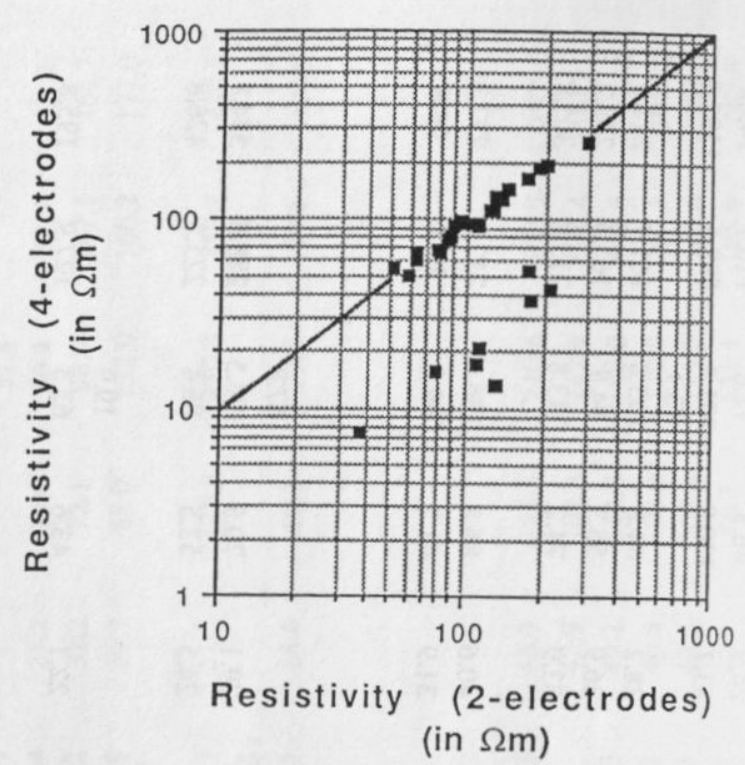

Fig. 7. Comparison of resistivity measurements made with a two- and a four-electrode set up. The departures from the 1:1 trend are due to occasional leaking in the unreliable fourelectrode set up.

error due to electrode potential is evaluated to be less than $15.0 \Omega \mathrm{m}$, which is acceptable for basalts with an average resistivity of about $150.0 \Omega$.m, but would is not acceptable for more conductive rocks. In order to study the interdependence between temperature and surface processes active at low salinity, the samples were placed in a poorly conductive bath $\left(R_{w}=43.7 \Omega . m\right.$ at $\left.23.5^{\circ} \mathrm{C}\right)$ and the temperature raised from $23.5^{\circ}$ to $70.0^{\circ} \mathrm{C}$.

Results

The results of the laboratory measurements are summarized in Table 1. Average values are reported in Table 3 with respect to lithologic type and large-scale layers of the oceanic basement.

Cation exchange capacity. A zonation of the results is observed according to depth and, consequently, alteration facies of the recovered rocks (Figure 8). This zonation is comparable to that observed in cores, thin sections, and geochemical logs [Alt et al., 1985, 1986; Laverne, 1987; Anderson et al., 1989] (Table 1). In the extrusive upper part of the basement, the quasi-uniform presence of saponite, a Fe-rich trioctahedral smectite, formed due to the alteration of olivine, is reflected by high values of CEC. For samples from the massive flows of layers $2 \mathrm{~A}$ and $2 \mathrm{~B}$, the average CEC is high $(5.8 \mathrm{meq} / 100 \mathrm{~g}$; Table 3$)$ in spite of a low average porosity (1.4\%; Table 3 ) and the absence of fractures in most of the samples. The fracture-free samples from the massive flows (Figure 8; small solid circles) are commonly hose with the lowest CEC values in this part of the crust. In the more porous and fractured pillows (open circles), the average CEC value increases to $10.2 \mathrm{meq} / 100 \mathrm{~g}$.

In the massive units of layer $2 \mathrm{C}$, where greenschist facies of alteration are observed, the average CEC value decreases 
TABLE 2. Measurements at Six Electrical Current Frequencies of the Resistance of Three Samples Selected from the Massive Unit

\begin{tabular}{|c|c|c|c|c|c|c|}
\hline \multirow[b]{2}{*}{ Frequency, $\mathrm{Hz}$} & \multicolumn{2}{|c|}{ Sample 34-1041 } & \multicolumn{2}{|c|}{ Sample 27-538 } & \multicolumn{2}{|c|}{ Sample 2D-563 } \\
\hline & Resistance, $\mathrm{k} \Omega$ & Phase, deg & Resistance, $\mathrm{k} \Omega$ & Phase, deg & Resistance, $\mathrm{k} \Omega$ & Phase, deg \\
\hline 10.0 & 4.66 & -1.6 & 5.91 & -0.7 & 5.16 & -4.4 \\
\hline 50.0 & 4.64 & -1.7 & 5.89 & -0.3 & 5.07 & -2.9 \\
\hline 100.0 & 4.55 & -1.5 & 5.89 & -0.2 & 5.08 & -2.7 \\
\hline 1000.0 & 4.46 & -1.7 & 5.87 & -0.3 & 5.01 & -2.5 \\
\hline 10000.0 & 4.42 & -1.8 & 5.84 & -0.4 & 4.93 & -2.3 \\
\hline 50000.0 & 4.38 & -2.4 & 5.74 & -1.5 & 4.79 & -2.8 \\
\hline
\end{tabular}

With seawater as saturating-fluid; $\mathrm{Rw}=0.195 \Omega \cdot \mathrm{m}$ at $25^{\circ} \mathrm{C}$.

TABLE 3. Average Physical Properties Measured in the Laboratory and Presented to Lithologic Types and Large-Scale Layers of the Oceanic Crust

\begin{tabular}{|c|c|c|c|c|c|c|c|}
\hline \multirow[t]{2}{*}{ Location } & \multirow{2}{*}{ Lithology } & \multicolumn{2}{|c|}{ Porosity } & \multicolumn{2}{|c|}{ Resistivity* } & \multicolumn{2}{|c|}{ CEC } \\
\hline & & $\%$ & s.d. & $\Omega . m$ & s.d. & $\mathrm{meq} / 100 \mathrm{~g}$ & s.d. \\
\hline DSDP Hole 504B & All samples & 2.7 & 2.1 & 116.1 & 69.2 & 8.1 & 5.8 \\
\hline Layers $2 \mathrm{~A}$ and $2 \mathrm{~B}$ & Pillow units & 2.3 & 0.7 & 89.5 & 35.6 & 10.2 & 6.3 \\
\hline Layers $2 \mathrm{~A}$ and $2 \mathrm{~B}$ & Massive units & 1.4 & 0.3 & 146.1 & 48.4 & 5.8 & 1.2 \\
\hline Layer $2 \mathrm{C}$ & Breccias & 8.7 & 5.9 & 39.9 & 21.9 & 9.8 & 5.3 \\
\hline Layer 2C & Massive units & 2.8 & 0.8 & 155.7 & 60.7 & 4.3 & 2.5 \\
\hline $\operatorname{EPR}\left(13^{\circ} \mathrm{N}\right)$ & Fresh Pillow & & & & & 1.1 & 0.2 \\
\hline
\end{tabular}

* $(\mathrm{Rw}=0.195 \Omega \cdot \mathrm{m})$

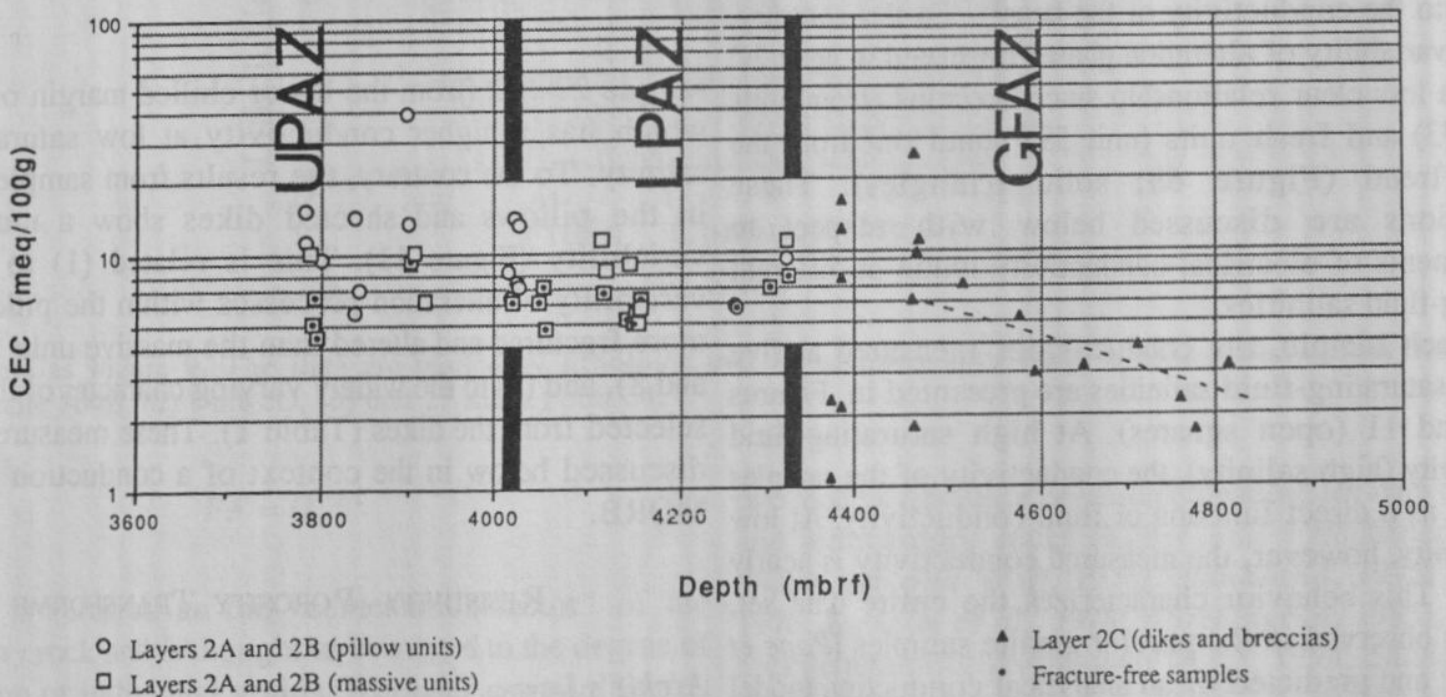

Fig. 8. Laboratory measurements of CEC plotted as a function of depth. The decrease in the amount of smectite (mostly saponites), from the upper part of the basement (layers $2 \mathrm{~A}$ and $2 \mathrm{~B}$ ) to the sheeted dikes of layer $2 \mathrm{C}$ (characterized by greenschist facies of alteration), is reflected in a decrease of the CEC within layer $2 \mathrm{C}$. The fracture-free samples of layers $2 \mathrm{~A}$ and $2 \mathrm{~B}$ have commonly the lowest CEC values in this part of the crust. The three main alteration zones observed in thin sections [Alt et al., 1985, 1986; Laverne, 1987] are indicated as UPAZ (upper pillow alteration zone), LPAZ (lower pillow alteration zone), and GFAZ (greenschist facies alteration zone). 
to $4.3 \mathrm{meq} / 100 \mathrm{~g}$. The greenschist facies are characterized in hole 504B by a smaller content of smectites than the upper part of the basement, more chlorites, and numerous poorly conductive minerals such as talc, quartz, calcite, epidote, and actinolite. The intense alteration associated with brecciated regions within the dikes is characterized by a high average CEC $(9.8 \mathrm{meq} / 100 \mathrm{~g})$ and a large variability (s.d. = 5.3 $\mathrm{meq} / 100 \mathrm{~g}$ ). This variability and the contrast with results obtained in dikes reflects the lack of lateral hydraulic connectivity in layer $2 \mathrm{C}$, which is also observed in the Semail ophiolite of Oman [Haymon and Koski, 1987; Nehlig and Juteau, 1988]. Besides such extreme segmentation, the low CEC values obtained for four samples (units 59,63 and 74) point to units intruded into a different alteration environment from that active at the ridge axis for the surrounding crust.

Porosity and electrical resistivity. The fracture-free samples from the massive flows of layers $2 \mathrm{~A}$ and $2 \mathrm{~B}$ (Figure $6 a$; open squares combined with a dot) are more resistive and less porous than fractured ones (open squares only) and those from the more altered pillows (open circles). This relationship was noticed in previous studies [Hyndman and Drury, 1976; Karato, 1985] and probably relates formation factor and fracture density, as proposed by Katsube and Hume [1987]. The samples from layer 2C (Figure $6 a$; solid triangles) exhibit generally higher resistivities than the samples from layers $2 \mathrm{~A}$ or $2 \mathrm{~B}$ for a given porosity, even though most of them are fractured or brecciated (Tables 1 and 2 ). Even higher values of resistivity are recorded in the massive units of layer $2 \mathrm{C}$, as verified in situ with values as high as $2000 \Omega$.m (Figure 5). Similarly, an inverse correlation between "apparent" formation factor and CEC is observed for samples from layers $2 \mathrm{~A}$ and $2 \mathrm{~B}$ (Figure $6 b$ ), and the fracture-free samples have the lowest CEC. This correlation confirms the contribution of the alteration minerals to the conductivity of the basalt. To the contrary, the large variability of alteration phases observed in layer $2 \mathrm{C}$ leads to a less clear relationship since breccias (from units 63 and 73) and fresh units (unit 59) stand out from the overall trend (Figure $6 b$; solid triangles). These observations are discussed below with respect to measurements of electrical conductivity made at different saturating-fluid salinities.

For each sample, the conductivities measured at five different saturating-fluid salinities are presented in Figures 9,10 , and 11 (open squares). At high saturating-fluid conductivity (high salinity), the conductivity of the samples increases as a direct function of fluid conductivity. At low fluid salinity, however, the measured conductivity is nearly constant. This behavior characterizes the entire data set. Such was observed in the past for granite samples [Pape et al., 1985] and predicted by an analytical conduction model for Icelandic basalts [Flovenz et al., 1985]. The data are presented by lithologic type in order to enhance similitudes and to contrast differences. In the massive units, the results are generally coherent (Figure 10). Unit 27 is the most resistive, whereas units $2 \mathrm{D}$ and 34 appear similar. The only departure from these homogeneous trends is shown by

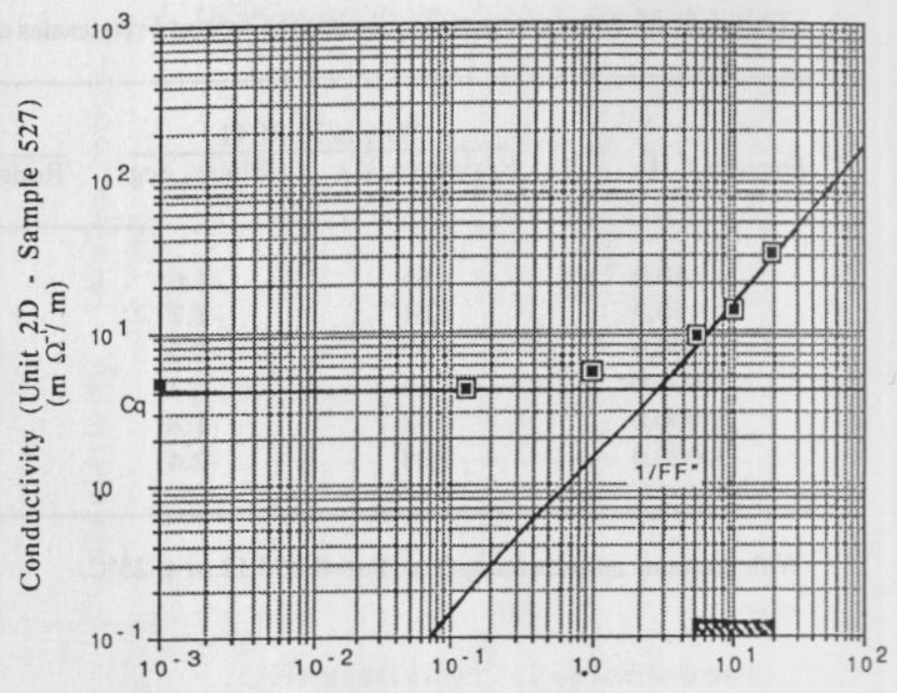

Saturating-Fluid Conductivity (in $\Omega / / m$ )

Fig. 9. Electrical conductivity of sample 527 from unit 2D (a massive flow), plotted versus saturating-fluid conductivity. The open squares represent measurements made at different saturating-fluid salinities, and the solid square on the vertical axis is derived from the CEC measurement using a surface conduction model (equations (4) and (6)). The horizontal asymptote is related to cationitic conduction on pore surfaces (in the bound-water domain), while the asymptote at high saturating-fluid conductivity (or salinity) corresponds to electrolytic conduction within the pore space (in the free-water domain). The shaded domain on the horizontal axis represents seawater conductivity in hole 504B due to due to temperature variations. A higher temperature, or a larger CEC value, tends to increase surface conduction $C_{q}$. The "intrinsic" formation factor is determined by the location of the high-salinity asymptote.

sample 27-622 (from the lower chilled margin of unit 27), which has a higher conductivity at low saturating-fluid salinity. To the contrary, the results from samples selected in the pillows and sheeted dikes show a much larger variability (Figure 11). This is related (1) to the large variability of alteration processes within the pillows, often more fractured and altered than the massive units (Figures 6 and 8), and (2) to the widely varying character of the samples selected from the dikes (Table 1). These measurements are discussed below in the context of a conduction model for MORB.

\section{RESISTIVITY - POROSITY TRANSFORMS}

\section{Archie's Law}

The first relationship between resistivity and porosity was proposed by Sundberg [1932] and experimentally derived for sedimentary rocks by Archie [1942] from the analysis of resistivity measurements obtained from cores. The formation factor was related to porosity by 

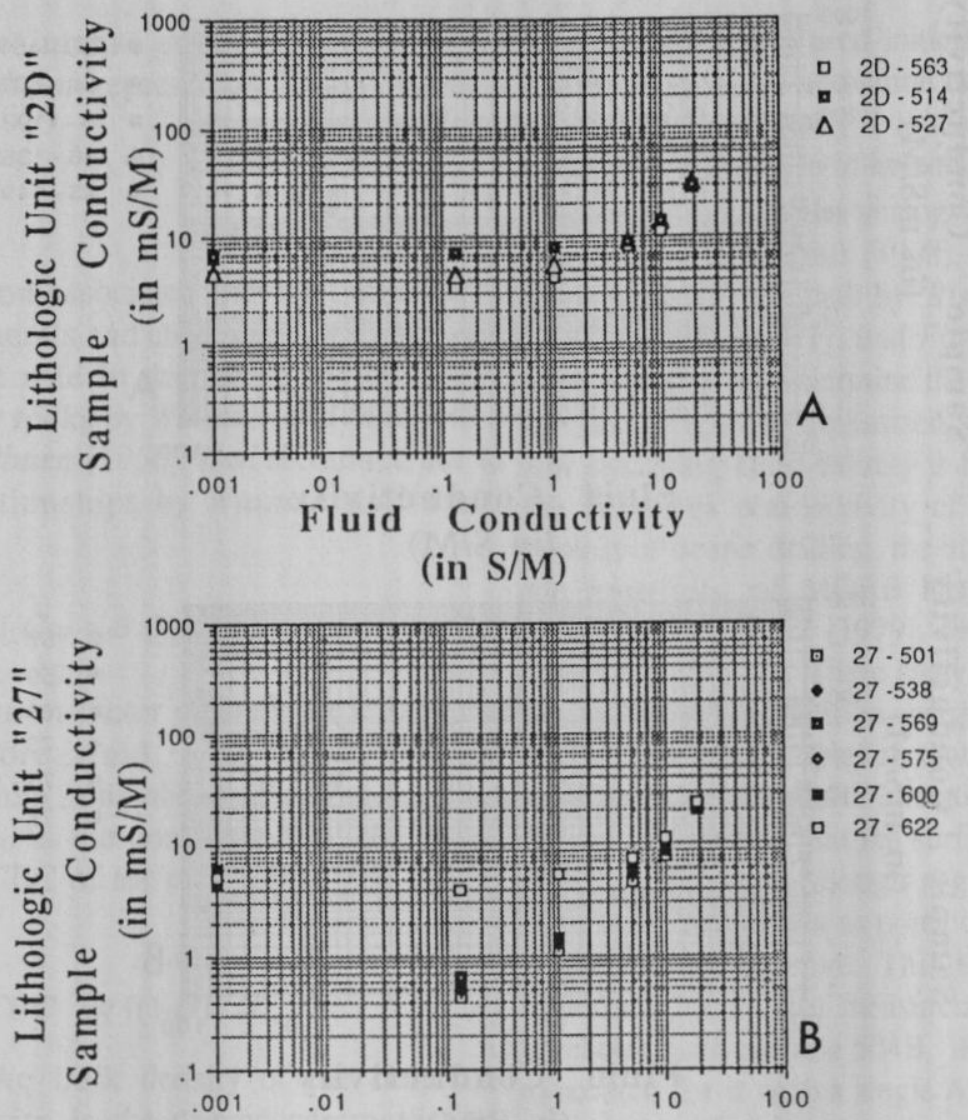

Fluid Conductivity (in $\mathrm{S} / \mathrm{M}$ )

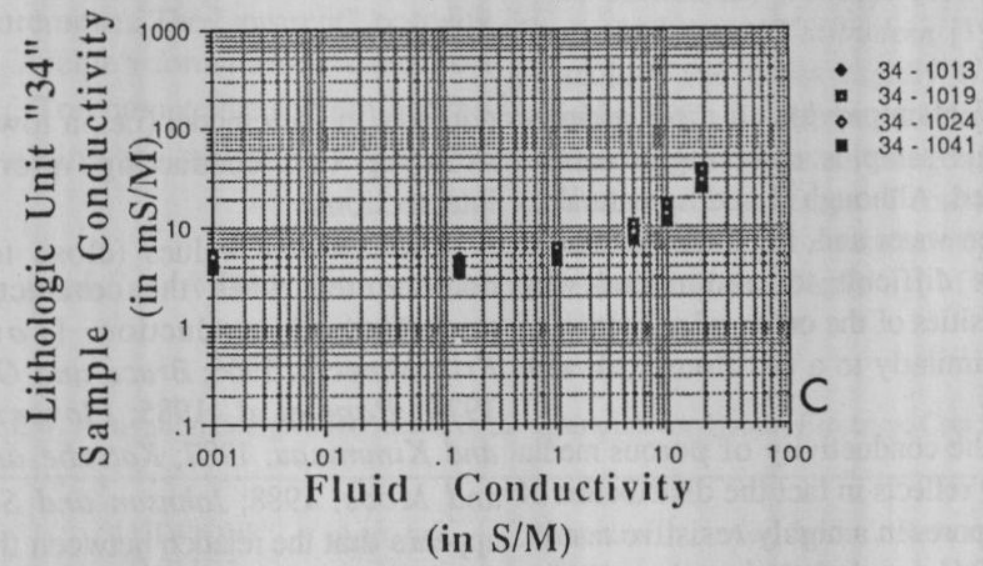

Fig.10. Same as Figure 9. The data are plotted by lithologic unit for samples from massive units penetrated in the volcanic section of hole 504B. (a) Unit 2D, (b) unit 27 and $(c)$ unit 34.

$$
F F=\emptyset^{-m}
$$

(1) two models has since been much debated for both crystalline and sedimentary rocks [Keller and Frischknecht, 1966; Shankland and Waff, 1974; Shankland, 1975; Madden,

where $m$ is referred as the "cementation factor" of the sedimentary rock and is thought to be related to the degree of cementation of individual grains. Winsauer and McCardell [1953] developed a more general relationship

$$
F F=a \emptyset^{-m}
$$

(2) Whereas Archie's empirical law (equation (1)) is a good 1976; Jackson et al., 1978; Worthington, 1985], and even Waff, 1977; Hermance, 1979]. A discussion of the different models and their implications is provided by Pezard et al. [1989], and can be summarized as follows. representation of the formation factor-porosity transform where the factor $a$ is a constant. The significance of these over several porosity decades [Archie, 1942; Brace et al., 

Smits model (which assumes constant charge) does not
hold. In hole 504B, a zeolite-rich zone is described by Alt et al. [1985, 1986] and Laverne [1987] from 528.0 to $574.0 \mathrm{mbsf}$, within the upper alteration zone (UPAZ). These zeolites are thought to have appeared due to a late phase of alteration of the upper crust, in relation with off-axis hydrothermal circulation of oxygenated fluids. Whereas pillow units have an average resistivity of about $10.0 \Omega$.m in layers $2 \mathrm{~A}$ and $2 \mathrm{~B}$, they average $25.0 \Omega \mathrm{m}$ in the zeoliterich zone. Besides the presence of resistive massive units, this response constitutes the only departure from an otherwise constant behavior (Figure 5). These in situ measurements show that zeolites are not as conductive at low temperature as the saponites generally found in layers 2A and 2B. As an approximation, zeolites are considered to follow the Waxman-Smits model (equation (3)) in this particular study.

\section{Crystalline Rocks}

The nature of the porosity of crystalline rocks is discussed in details by Brace [1971], Mathews et al. [1983], Becker [1985] and many others. It is generally described as made of three types of pores, (1) equant vesicles, mostly absent in the cores recovered from hole 504B, and grain boundaries that might create a poorly connected path for electrical current, (2) microcracks (present at the scale of individual minerals), often defined as spaces with a characteristic length of about $100 \mu \mathrm{m}$ and an aspect ratio from $10^{-3}$ to $10^{-5}$ [Simmons and Richter, 1974]; as such, these microcracks are possible candidates to constitute the small-scale network required by low $m$ values, and (3) large open cracks and voids commonly encountered within seismic layer 2A [Houtz and Ewing, 1976; Newmark et al., 1985] and associated with collapse structures that might have originated from drained pillow lava, flow breccias, talus, and rubble [Mathews et al., 1983; Hekinian, 1984]. These large fractures are either plugged with alteration products or filled with fluid, in which case they constitute the main permeability channels within the upper oceanic basement. Such porosity cannot be studied in the laboratory, stressing the need for in situ experiments to obtain an accurate representation of physical properties in the upper crust. The first two types of pore space are typically found in cores analyzed in the laboratory. Porosity-formation factor relationships might consequently vary from in situ to laboratory data sets, and care should be exerted when comparing them. Over the years, many authors have tried to relate porosity to the formation factor of MORB with mainly two types of regressions, both similar to Archie's empirical formula. In the first category of regression, $a$ is 1.0 as in Archie [1942] and Brace et al. [1965] (equation (1)). In the second category, $a$ is larger than 1.0 , as often suggested for this type of pore topology [Flovenz et al., 1985; Schwartz and Kimminau,1987; Katsube and Hume, 1987; Broglia and Moos, 1988; Pezard et al., 1989].

In a study of $110 \mathrm{Ma}$ basalts from hole $418 \mathrm{~A}$, Broglia and Moos[1988] have calibrated the response of in situ measurements versus core data, then analyzed the downhole data in a discriminating approach over sections of good log quality (such as those of small borehole size). In the extremely altered upper part of the basement, $a=11.5$ and $m=1.85$, which is similar to the results derived from logs by Kirkpatrick [1979] in hole 396B. The lower and fresher part of hole $418 \mathrm{~A}$ gives a different relation with $a=29.5$ and $m=1.16$. $M$ is consequently larger in the altered section, possibly due to an increased tortuosity of the pore space associated with intense hydrothermal alteration. The value of 1.85 obtained in the most altered section is similar to that derived routinely for intergranular pore space [Archie, 1942; Jackson et al., 1978]. On the other hand, the low $m$ value in fresher rock suggests a pore space consisting mainly of microcracks. The factor $a$ remains large in both cases and is reported to decrease with increasing alteration.

Similarly, in a study of subaerial basalts from Iceland, Flovenz et al. [1985] concluded that Archie's law was not valid in freshwater environments. The fracture porosity, fluid resistivity, temperature, and formation factor were related in a theoretical model with $a=8.7$ and $m=1.06$. Due to the low salinity of groundwater in Iceland (with a salinity of the order of 1.0-100.0 $\Omega \cdot \mathrm{m}$ at $25^{\circ} \mathrm{C}$ ), the electrolytic component of current conduction was neglected and surface conduction considered to be the dominant conduction mechanism. As seawater conductivity is at least one order of magnitude larger than that of groundwater in Iceland, the results of Flovenz et al. are not directly applicable to the analysis of the oceanic crust. Their model, however, predicts the behavior of basalt conductivity at varying saturating-fluid salinities used in the present dataset (Figures 9, 10, and 11), and describes the temperature dependence of basalt conductivity. In hole 504B, the preliminary study of the resistivity-porosity transform led to a relation with $a=9.1$ and $m=1.05$ [Pezard et al., 1989].

\section{Electrical Conduction in MORB}

The model represented by Figure 9 is similar to that of Florenz et al. [1985] for subaerial basalts and Pape et al. [1985] for granite. This model is based on two principal modes of current conduction active within the rock. At low saturating-fluid salinity, surface conduction on the outer surfaces of alteration minerals dominates and Archie's formula does not hold [Waxman and Smits, 1968; Rink and Schopper, 1974; Clavier et al., 1977; Ucok, 1979; Florenz et al., 1985; Pape et al., 1985]. At high fluid salinity, surface conduction may be neglected and electrolyte conduction is prevalent. Whereas the latter is well-known and can be described by a simple relation in which conductivity depends on salinity and temperature [Parkhomenko, 1967; Ucok, 1979; Olhoeft, 1981], the former has not been studied as extensively and requires a brief review of the physics active at the fluid-mineral interface.

Surface processes. All surfaces carry excess charges due to free-surface phenomena. Alteration minerals are often organized in sheet-like structures characterized by a 
deficiency of positive electrical charges. Large surface areas appears constant as long as cations constitute a continuous carrying a strong negative electrical field are consequently current path through the rock (Figures 9, 10 and 11). It offered to fluid contact, and tend to adsorb the cations present should be noticed that surface conduction does not in solution. The structure of the mineral-liquid interface may necessarily require saturation of all the potential adsorbtion be represented by a simple model (Figure 12), with hydrated- sites, which might explain the constant conductivity sodium ions located near the pore surface. These absorbed obtained at low salinity. As the fluid salinity increases, the cations constitute a planar diffuse layer that constitutes a conductivity remains constant as the outer layer compresses, path for electrical current (often referred to as the "Stern- until saturation of all the potential hydroxyl-sites on the Gouy layer" or the "outer Helmholtz plane"). Until recently altered surfaces. At higher salinity, excess cations remain in [Johnson and Schwartz, 1989], theoretical developments for the electrolyte and the conductivity of the rock increases the description of surface conductance in porous media have with that of the pore fluid (Figure 9).

met large difficulties due to the complex topology of alteration mineral surfaces [Matijevic, 1974]. Experimental studies have nevertheless permitted to identify the main physical parameters contributing to surface conduction [Rink and Schopper, 1974; Clavier et al., 1977; Pape and Worthington, 1983; Pape et al., 1985].

Comparison with experimental data. Assuming arbitrarily $\mu^{2}=10.0$ (as proposed by Pape et al. [1985] for granite or Wilkens et al. [1989] for oceanic basalts), a theoretical surface conductivity $C s$ based on CEC measurements was computed for each sample and plotted on the $Y$ axis of the conductivity diagrams (Figures 9,10 , and

Analytical model. For constant-charge clay surfaces, 11). In the case of massive units 2D and 34 (Figure $10 a$ and cationic conduction is related to the surface area of the $10 \mathrm{c}$ ), the correspondence between this model and the low mineral-fluid interface $A$, the density of cations per unit salinity measurements of conductivity $\left(R_{W}=7.93 \Omega . \mathrm{m}\right)$ is area $\Sigma$, and $B$ the mobility of these cations within the outer Helmholtz plane. The conductivity of pore surfaces $C_{S}$ may thus be represented with

$$
C_{s}=\left[B Q_{\nu}\right] / F F^{*}=[B(A \Sigma)] /\left[\mu^{2} F F^{\prime \prime}\right]
$$

where $F F^{*}$ is the formation factor associated with surface conduction, $\mu 2$ is a factor $(>1.0)$ related to the tortuosity of pore surfaces [Pape et al., 1985]. The conductivity of the electrolyte $C_{f}$ is written

$$
C_{f}=\left[C_{w} / F F^{\prime \prime}\right]
$$

(7) free-water electrical conduction, and computed from excellent. This is not the case for the samples from unit 27 (Figure $10 \mathrm{~b}$ ), where a $\mu^{2}=100.0$ would seem more appropriate. In the pillow units (Figure 11a), the fit of the surface conduction model is somewhat variable, but $C_{S}$ remains within an order of magnitude of the resistivity measurements made at low salinity. This is also true for the samples from the sheeted dikes (Figure 11b), with a general tendency to overestimate $C_{s}$ (or underestimate $\mu^{2}$ ) as observed previously for unit 27 . The "intrinsic" formation factor (used in the computation of $C_{s}$ ) is associated with measurements made at high fluid salinity, where electrolytic where $C_{w}$ depends on temperature (equation (10)), and the conduction is dominant and surface conduction negligible total conductivity of the fluid-rock assemblage is

(Figure 10) with

$$
C_{o}=\left[C_{f}+C_{s}\right]=\left(C_{w} / F F^{\prime \prime}\right)+\left(\left[B Q_{\nu}\right] /\left[\mu^{2} F F^{\prime \prime}\right]\right)
$$

At low salinity, all the cations in solution are absorbed onto pore surfaces and the conductivity of the samples

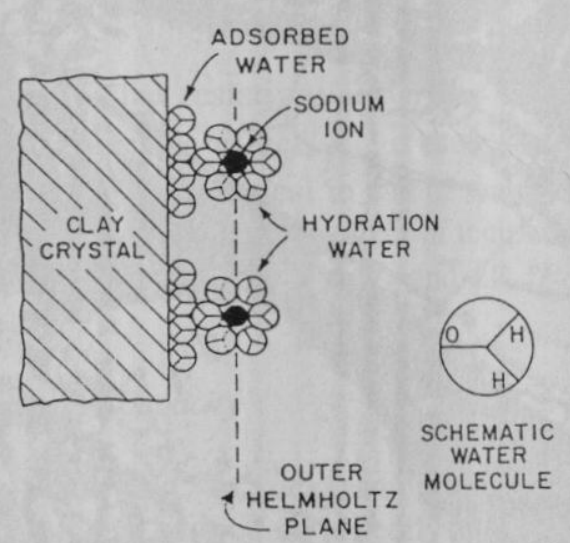

Fig. 12. Schematic view of an the adsorbed fluid layer onto pore surfaces [from Clavier et al., 1977], often referred to as the outer Helmholtz plane or the Stern-Gouy diffuse layer [Ucok, 1979].

$$
F F^{\prime \prime}=\left[C_{w} / C_{o}\right]
$$

As a consequence, the relative importance of the two conduction mechanisms active in the upper oceanic crust during in situ experiments may be estimated from laboratory data. Considering that the conductivity of seawater changes

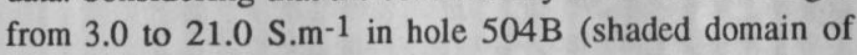
Figure 9) as the temperature increases, the dominant conduction mechanism in massive units is electrolytic. In the pillow units, where the amount of alteration is larger, the crossover point between cationic and electrolytic conduction mechanisms is shifted to the right of the plot, and surface conduction is predominant. Different physical processes are consequently activated in different lithologies during in situ experiments. The in situ measurements are analyzed thereafter on the basis of this experimental model.

Temperature dependence. The results of previous studies describing influence of temperature on the electrical conductivity of MORB [Olhoeft,1977; Ucok,1979; Drury and Hyndman,1979; Flovenz et al.,1985; Karato,1985] have been computted in terms of activation energies (expressed in kiloJoule per mole), compiled in Table 4 and 
compared with the present data set. Table 4 shows that the low activation value implied by the law used by Von Herzen et al. [1983] is somewhat in contradiction with the results of Olhoeft [1977, 1981], as it would not allow surface conduction to become the dominant conduction process above $80^{\circ} \mathrm{C}$. An average value of 11.95 kiloJoule per mole is obtained with the present data and that of Karato [1985] in massive units. This value was used to correct the logs for both electrolytic and cationitic conduction mechanisms. For equation (5) and

$$
C_{w}=C_{w o} \exp \left[-E_{a w} / R T_{K}\right],
$$

$B_{o}$ and $C_{w o}$ were computed to meet (1) the laboratory results obtained at low fluid salinity and (2) the constraint imposed by $R_{w}=0.20 \Omega \cdot \mathrm{m}$ at $25^{\circ} \mathrm{C}$, respectively.

Porosity-resistivity transform. In order to have an homogeneous dataset in terms of rock-type, the "intrinsic" formation factor (related to electrolytic conduction only) of samples from massive units only is computed from the conductivity diagrams (Figures 10 and 11), and plotted against measured porosity (Figure 13). The regression obtained has a high correlation, is different from Archie's to pore volume processes (in the flows). The regression law, but similar to the results of Flovenz et al. [1985], obtained from massive units is consequently prefered in the Pape et al. [1985], and Broglia and Moos [1988] with

$$
F F^{\prime \prime}=[a / \varnothing]=[(10.0) / \emptyset] \text {. }
$$

The low $m$ value constrains a conducting pore space Pape et al., 1982, 1985; Wong, 1988].

made of cracks and microcracks (Figure 14, Table 5). The Equation (11) is in fact similar to the models of Carman samples from dikes and pillows were not used in this [1956], Ward and Fraser [1967], Snow [1968], Norton regression due to the large variability of their structures and Knapp [1977], Walsh and Brace [1984], Patterson (often fractured or brecciated) and respective alteration facies, [1983], Pape and Worthington [1983], Katsube and Hume leading to an even more extreme representation with $a=59.2$ [1987], and Wilkens et al. [1988]. In spite of the variety of and $m=0.58$. Mixing data from massive and pillow units approaches in these studies, and even though a large would imply associating surface processes (in the pillows) terminological spectrum is used, $F F^{\prime \prime}$ is in each case related

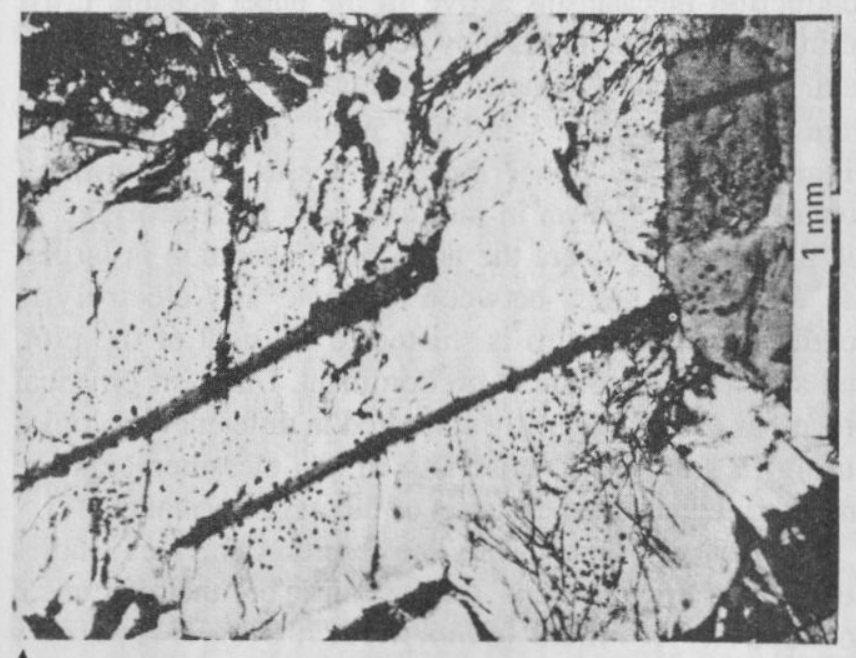

A

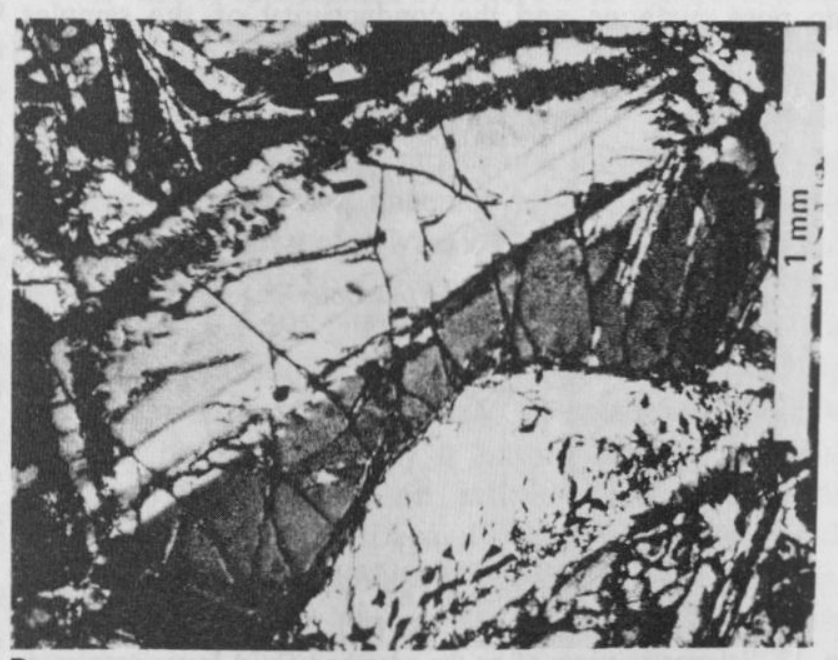

B

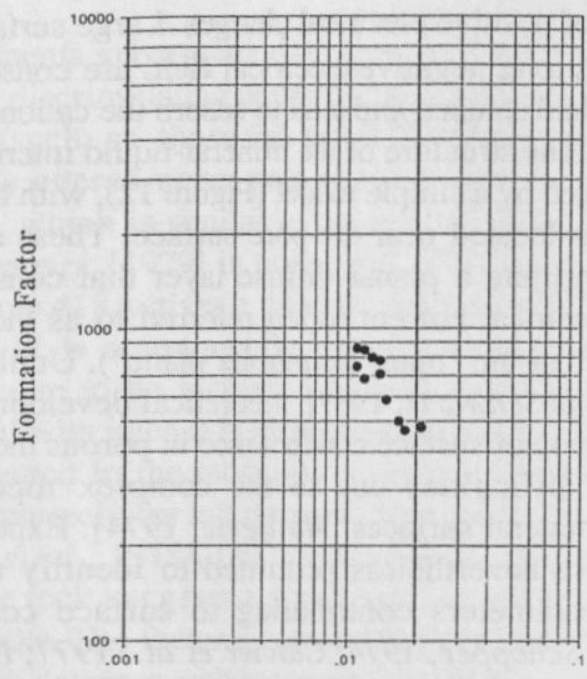

Porosity

Fig. 13. "Intrinsic" formation factor of massive basalt samples plotted as a function of porosity.

following analysis of in situ measurements, with the implicit assumption that the small-scale structure of the pore space (Figure 13) might be self-similar to larger eatures not sampled by the minicores [Sen et al., 1981;

Fig. 14. Examples of microcracks observed at mineral scale. (a) Sample 102-2 (24-27 cm) and (b) $90-4$ (49-53 cm) represent plagiocase crystals viewed in crossed nicols [after Kempton, 1985]. 
TABLE 5. Review of Archie's Law Parameters for Crystalline Rocks

\begin{tabular}{|c|c|c|c|c|c|c|c|}
\hline Context & Drill Hole & Location & Age, Ma & Rock Type & a & $\mathrm{m}$ & Source \\
\hline \multirow[t]{5}{*}{ Oceanic } & $396 \mathrm{~B}$ & Mid-Atlantic Ridge & 13 & basalt & 12.50 & 1.33 & Core/Log \\
\hline & 417D & Bermuda Rise & 109 & basalt & 11.40 & 1.20 & Core \\
\hline & & & & basalt & 26.40 & 0.88 & $\log$ \\
\hline & $418 \mathrm{~A}$ & Bermuda Rise & 109 & basalt (fresh) & 29.50 & 1.16 & Log \\
\hline & & & & basalt (altered) & 11.50 & 1.85 & Log \\
\hline Continental & Falkenberg & $\begin{array}{l}\text { Costa Rica Rift } \\
\text { Oberpfalz, Germany }\end{array}$ & $\begin{array}{l}5.9 \\
\text { craton }\end{array}$ & $\begin{array}{l}\text { basalt } \\
\text { granite }\end{array}$ & $\begin{array}{l}9.10 \\
4.10\end{array}$ & $\begin{array}{l}1.0 \mathrm{~J} \\
1.08\end{array}$ & $\begin{array}{l}\text { Core } \\
\text { Core }\end{array}$ \\
\hline
\end{tabular}

With $a \neq 1.0$ reported in the literature

to porosity $\emptyset$ and a "tortuosity factor" of the pore space $\pi^{2}$ with

$$
F F^{\prime \prime}=\left[\pi^{2} / \emptyset\right]
$$

The values of $\pi^{2}$ are found to vary from unity to a few tenths. The term $\pi^{2}$ may be associated in this case with $a$ of equation (11), or compared to the term $a_{3}$ used by Johnson and Schwartz [1989] to model the tri-dimensional tortuosity of the pore space, whereas $\mu^{2}$ could be related to $a_{2}$ defined by the same authors as the tortuosity of the pore surfaces.

\section{ANALYSIS OF IN SITU MEASUREMENTS}

\section{Shipboard Analysis}

The relationship between porosity and resistivity for basaltic rocks is discussed by Becker [1985], who used Archie's formula $(a=1.0$ and $m=2.0)$ to relate resistivity to porosity in basaltic rocks. The same reasoning was initially used on board ship during ODP leg 111 to obtain a preliminary porosity estimate (Figure 5) with

$$
\emptyset_{a}^{2}=\left[R_{w} / L L d_{c}\right]
$$

where $L L d_{c}$ is the resistivity from the deep laterolog corrected for borehole effect, $R_{w}$ is the resistivity of the pore fluid, considered identical to that of seawater [Mottl et $a l ., 1983]$ and corrected for the effect of temperature. $\emptyset_{a}$ is clearly overestimated in layers 2A and 2B [Pezard and Anderson, 1989].

\section{Cation Exchange Capacity}

Although the CEC of rock samples can be measured experimentally, it cannot be directly and continuously measured at present in a borehole. The measurement of CEC is therefore limited to either in situ pointwise complexresistivity experiments, or to chemical analysis in the laboratory. Such difficulty has constrained the reconstruction of CEC profiles from other continuous measurements, on the basis of the calibration points obtained in the laboratory. The recent development of geochemical logging has, in particular, provided a way to extract petrophysical parameters (such as the CEC) from the derived mineralogy [Herron, 1986]. Assuming that the relative proportions of each alteration mineral of known CEC is provided from the geochemical log-derived mineralogy, an estimate of the CEC of the rock assemblage can be computed using a linear summation. The mineralogical inversion of the geochemical data recorded in hole 504B is described by Anderson et al. [1989], and the results are reported in Figure 15. The elemental composition has been solved for the presence of (1) smectite- and potassium-rich clays $(50 \mathrm{meq} / 100 \mathrm{~g})$, and (2) chlorite $(10 \mathrm{meq} / 100 \mathrm{~g})$. The agreement between the reconstructed CEC curve and laboratory measurements of CEC is good throughout the hole (Figure 15), although (1) more measurements in the altered upper part of the hole would be desirable, and (2) the amount of smectite is probably over estimated in layer $2 \mathrm{~A}$. This last point might originate in the mineralogical inversion because potassiumenrichment within this zone is included in the mineralogy inversion as smectite, instead of the more appropriate potassium-rich zeolites and clays.

\section{Porosity Models}

Besides shipboard analysis, new estimates of porosity were computed in relation with the previous experimental analysis, with $a$ and $m$ set to 10.0 and 1.0, respectively. Equations (8) and (11) were applied to in situ measurements with

$$
\begin{aligned}
& C L L d_{c}=\left[C_{w}+\left(B Q_{v} / \mu^{2}\right)\right] / F F^{\prime \prime} \\
& \emptyset_{k}=a C L L d_{c} /\left[C_{w}+\left(B Q_{v} / \mu^{2}\right)\right] .
\end{aligned}
$$

From the definition of the "intrinsic" formation factor $F F^{\prime \prime}$ expressed in equation (11), the porosity profiles PHIP3 $\left(\mu^{2}=10.0\right)$ and PHIP4 $\left(\mu^{2}=1.0\right)$ computed with equation (15) are related to $\emptyset_{k}$, the free-water fraction of the porosity (Figure 16), which is the hydraulically interconnected 


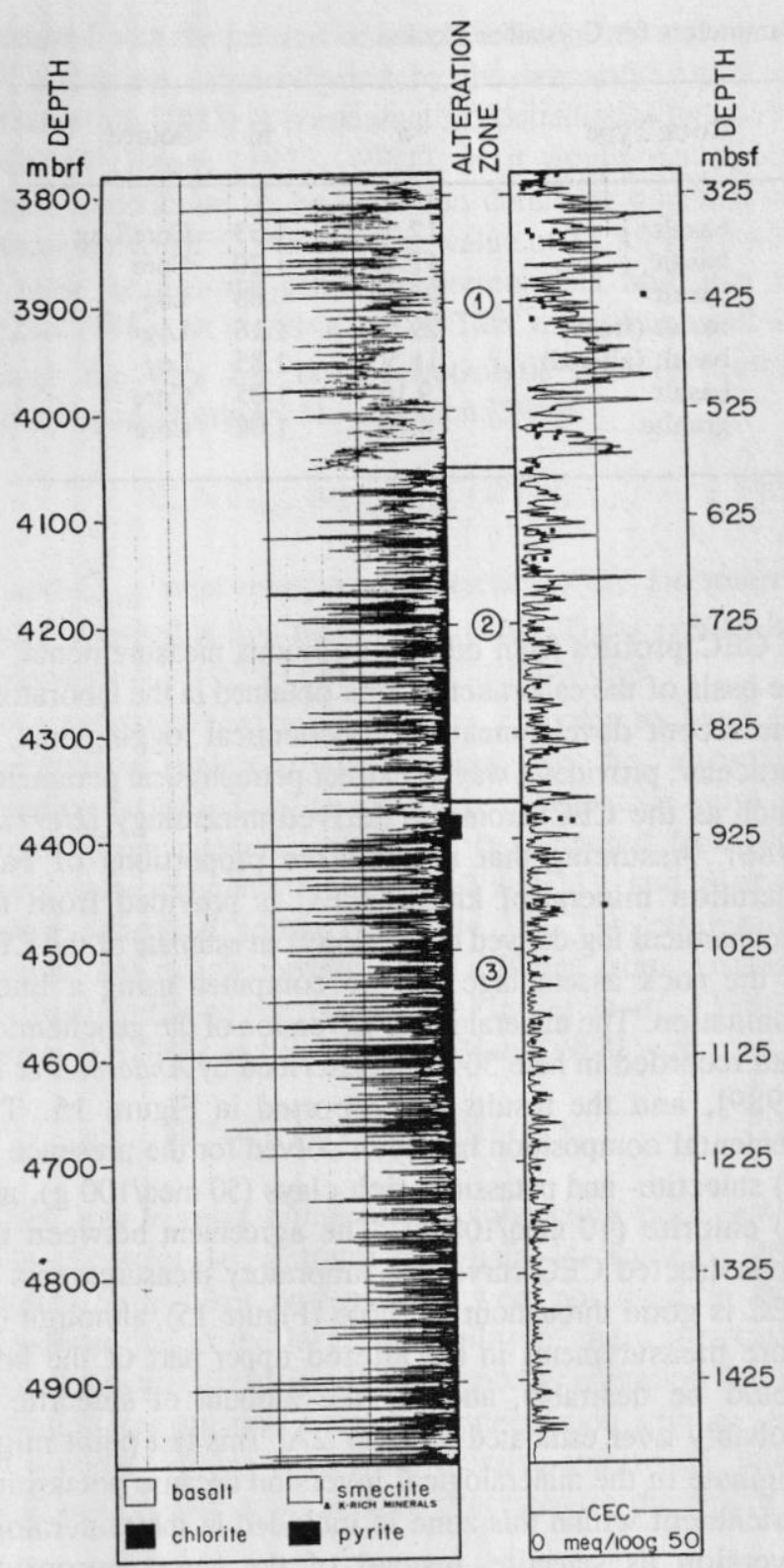

Fig. 15. Simplified mineralogy derived from the analysis of the geochemical logs data [Anderson et al., 1989] and CEC profile estimated from the geochemical logs data; the solid dots are the CEC measurements made on cores [Pezard et al., 1989]. The three main alteration zones observed in thin sections [Alt et al., 1985, 1986; Laverne, 1987] are indicated as UPAZ (upper pillow alteration zone), LPAZ (lower pillow alteration zone), and GFAZ (greenschist facies alteration zone).

porosity. The profile PHIR obtained with equation (12) which is based on Archie's law represents the fraction of the pore space occupied both by free- and bound-water (water molecules free to move in the electrolyte and absorbed onto alteration mineral surfaces).

Since the choice of $\mu^{2}$ is related to the nature of the Figure 17 with $\mu^{2}=10.0$ (for PER32) and $\mu^{2}=1.0$ (for pore surfaces, it seems natural to discuss the adequacy of, PER42).

different models with respect to the three main alteration Figure 17 shows a good correspondence between in situ zones defined by Alt et al. [1985, 1986] and Laverne permeability measurements and the model (equation (17)). [1987]. As $\mu^{2}$ cannot be continuously evaluated in situ, The fit between PER32 $\left(\mu^{2}=10.0\right)$ and measurements from

two realistic values based on those quoted in the litterature are tested in the following analysis. The free-water porosity profile computed with equation (14) and $\mu 2=10.0$ (PHIP3) at the base of layer 2B (in LPAZ, from 4050.0 to $4370.0 \mathrm{~m}$ ) shows porosity values up to $16.0 \%$, which is too high to be compatible with low in situ measurements of permeability. The profile obtained with $\mu 2=1.0$ (PHIP4) does not show the same contradiction in this interval, with an average value of $2.0 \%$ in the more porous section. Such a low value for $\mu^{2}$ points to extremely smooth pore surfaces, possibly due successive periods of alteration at high water/rock ratio [Alt et al., 1985, 1986; Laverne, 1987]. In the UPAZ (from basement top to $4050 \mathrm{~m}$ ), PHIP4 is again a better porosity estimate than PHIP3, which is often too large, and an intermediate value would seem more appropriate. The most porous section is located below unit $2 \mathrm{D}$, where the underpressured aquifer was discovered, and some highporosity intervals are also present above unit $2 \mathrm{D}$. Extremely low values of free-water porosity are obtained in the sheeted dikes in both cases. Although PHIP3 appears more realistic $\left(\mu^{2}=10.0\right)$, a higher value for $\mu^{2}$ constraining very tortuous pore surfaces would be acceptable.

\section{Permeability Models}

On the basis of Poiseuille's law, the fluid flow, electrical conductivity, and permeability of rocks have been related by Hubbert [1956] and Brace [1977] with

$$
K=\left(h^{2} / \beta\right) F F^{\prime \prime-2.00} \emptyset^{-1.00}
$$

where $K$ is the computed permeability of the rock, $\beta$ is a factor between 2.0 and 3.0 dependent on pore shape, $h$ is the hydraulic radius of the pore space, and $F F^{\prime \prime}$ is the "intrinsic" formation factor of the rock. When applied to crystalline rocks, this equation showed that porosity and permeability can be related linearly [Norton and Knapp,1977;Walsh and Brace,1984; Katsube and Hume,1987; Johnson and Schwartz,1989] with (11) and (15) which yield

$$
\begin{aligned}
K & =\left[\left(h^{2} \mid \beta a\right) \emptyset=\right. \\
& =\left[\left(h^{2} \mid \beta a\right) C_{L L d c}\right] /\left[C_{w}+\left(B Q_{v} / \mu^{2}\right)\right]
\end{aligned}
$$

with $a=10.0$ determined experimentally from the porosityresistivity transform (equation (11)). For basalts from hole $504 \mathrm{~B}, h$ has been reported equal to $10.0 \mu \mathrm{m}$ from the analysis of thin sections [Karato, 1985]. $\beta$, a constant between 2.0 and 3.0 after Brace [1977], is unknown and arbitrarily chosen equal to 2.5 . These values and equation

(17) were used to compute the two permeability profiles of

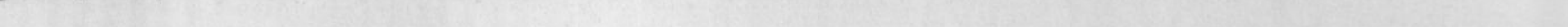




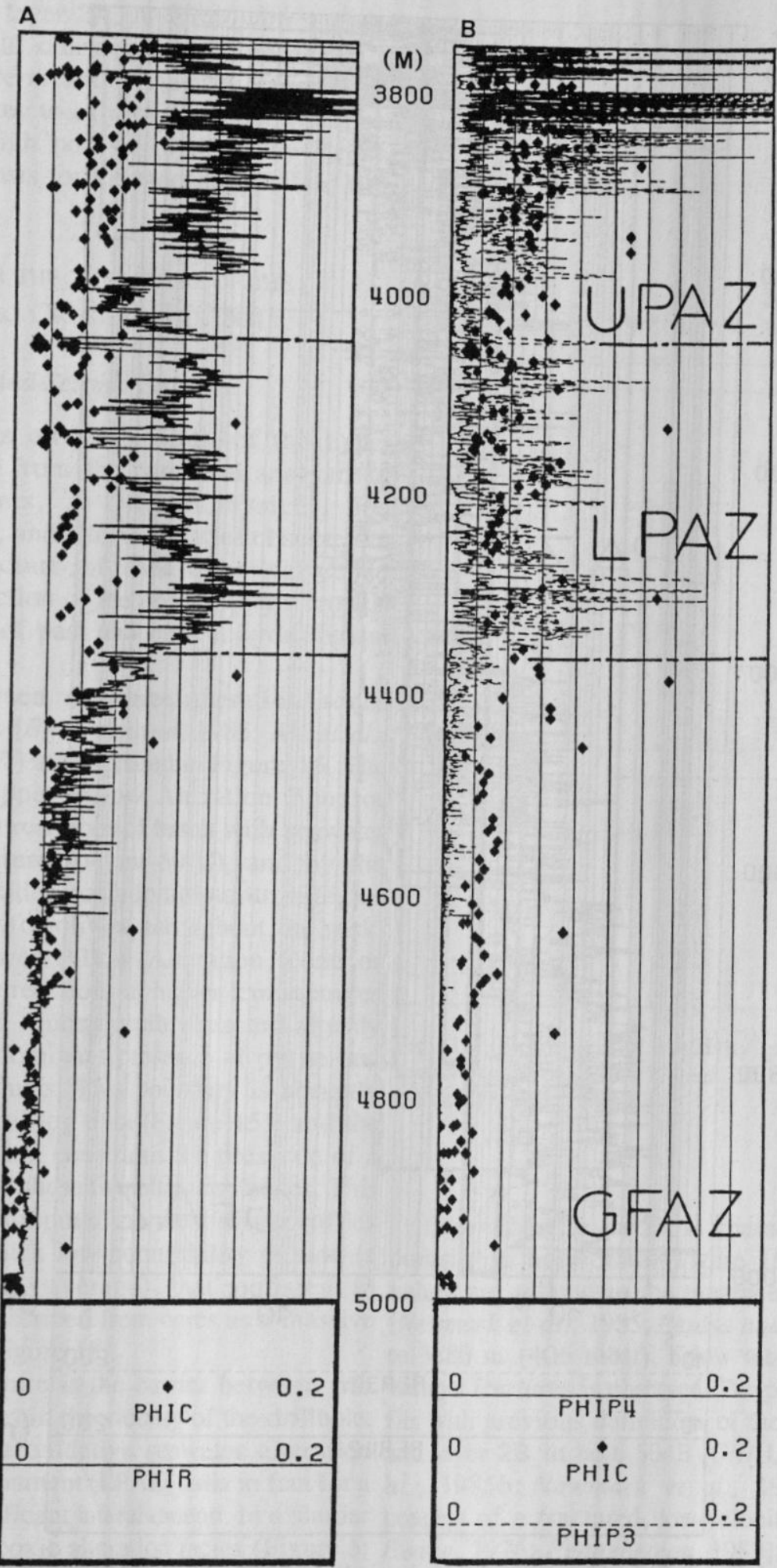

Fig. 16. (a) "Apparent" porosity profile computed from Archie's law (PHIR) during ODP leg 111. The conduction due to alteration minerals is not taken into account. $(b)$ Clay-corrected free-water porosity profiles computed from the new model with $\mu^{2}=10.0$ (PHIP3), and $\mu^{2}=1.0$ (PHIP4). The square diamonds represent porosity measurements made on cores. Alteration zonation (UPAZ, LPAZ, and GFAZ) as in Figure 15.

packer experiments is excellent in the dikes. At the base of interval tested in situ $(4000-4800 \mathrm{~m})$ is recomputed with a layer 2B (LPAZ), about an order of magnitude separates in more appropriate choice of parameters (fluid compressibility situ measurements and the computed permeability and viscosity) than those initially used. An increase of about (PER42). This difference might be reduced if, as noticed by an order of magnitude could be expected from this new Becker [1989], the permeability value for the longest computation. The section of highest porosity (Figure 16) 


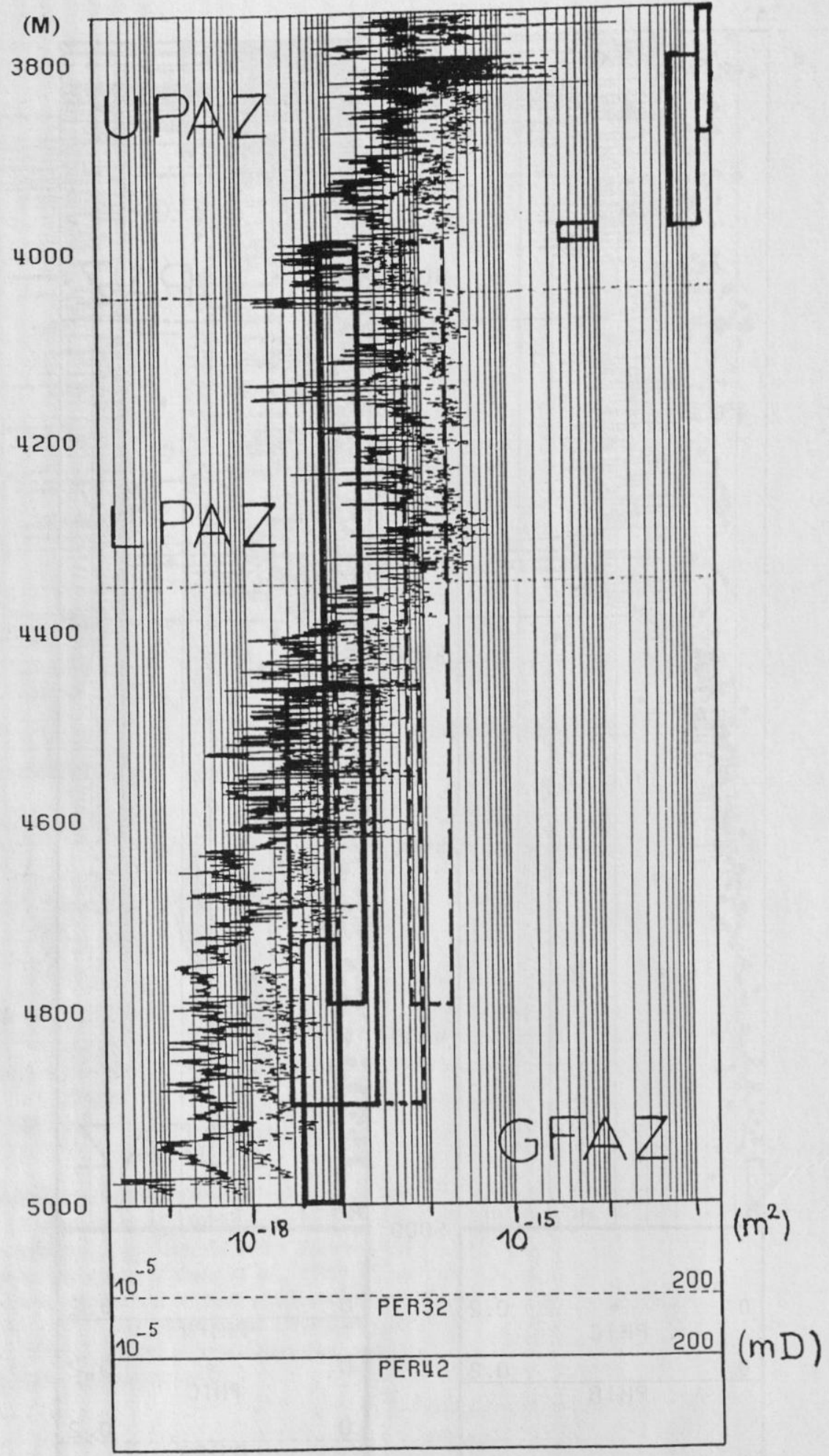

Fig. 17. Computed permeability profiles plotted in millidarcies and obtained with $\mu^{2}=10.0$ (PER32) and $\mu^{2}=1.0$ (PER42). The bulk permeabilities measured in situ are represented with elongate vertical rectangles. The vertical extent of the rectangle represents the depth interval over which average permeabilities were measured. The horizontal extent of the rectangles represents the range of estimated errors in the permeability determination [after Becker et al.,1989]. The two dashed rectangles indicate new estimates of permeability from in situ packer experiments computed with revised parameters [Becker, 1989; Becker et al., 1989]. Alteration zonation (UPAZ, LPAZ, and GFAZ) as in Figure 15.

and permeability (Figure 17) equates to the depth where an occur because logging data, such as the resistivity measured aquifer was discovered. Besides the anomaly in LPAZ, the with the DLL, provide average values of physical properties computed permeability tends to under-estimate the over a few cubic meters of rock. This averaging prevents a permeability measured in situ with a packer. This might precise description of sharp variations of permeability such 
as those encountered in layer $2 \mathrm{~A}$. A sensor with a higher vertical resolution would consequently be necessary to provide a more accurate permeability estimate. Nevertheless, this analysis provides a key to explain the paradox between low permeability and high porosity outlined by Becker [1985], and a working basis for the modeling of fluid flow within the oceanic crust.

\section{IMPLICATIONS FOR THE STRUCTURE OF THE UPPER OCEANIC CRUST AT STTE 504}

\section{Alteration, Morphology, and Seismic Structure}

A series of contraints on the structure of the upper oceanic crust is derived from the combined analysis of laboratory measurements, in situ geophysical and geochemical experiments, and alteration facies observed in thin sections. The structure of each seismically and hydrologically defined section of the upper oceanic crust is discussed in the context of past and present hydrological regimes.

The boundaries between the three alteration zones observed in thin sections [Emmermann, 1985; Alt et al., 1985, 1986; Laverne, 1987] are included in Figure 15. The upper alteration zone (Upper Pillow Alteration Zone or UPAZ) is characterized by reactions of basalt with seawater occuring at low temperature (below $60^{\circ} \mathrm{C}$ ), and by the presence of iron hydroxides, celadonite-nontronite, or saponite as a replacement for olivine throughout the rock. The middle section (Lower Pillow Alteration Zone or LPAZ) is characterized by reactions at higher temperatures $\left(60^{\circ}-110^{\circ} \mathrm{C}\right)$, with evolved fluids possibly reacted already within the crust, and the dominant presence of pyrite and saponite as alteration products. This boundary is abruptly outlined by the geochemical log data (Figure 15), and the

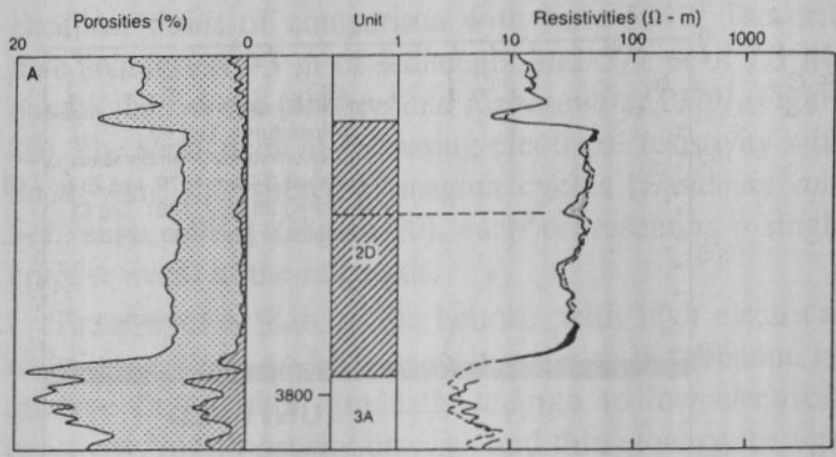
strong mineralogical zonation constrains the presence of a permeability barrier between these two alteration zones. This barrier appears on the computed-permeability profiles (Figure 17) with a 15-m-thick low-permeability section (a few microdarcies on the average) that equates to
lithostratigraphic unit 27 described from cores as a massive flow [Cann, et al., 1983] (Figure 18).
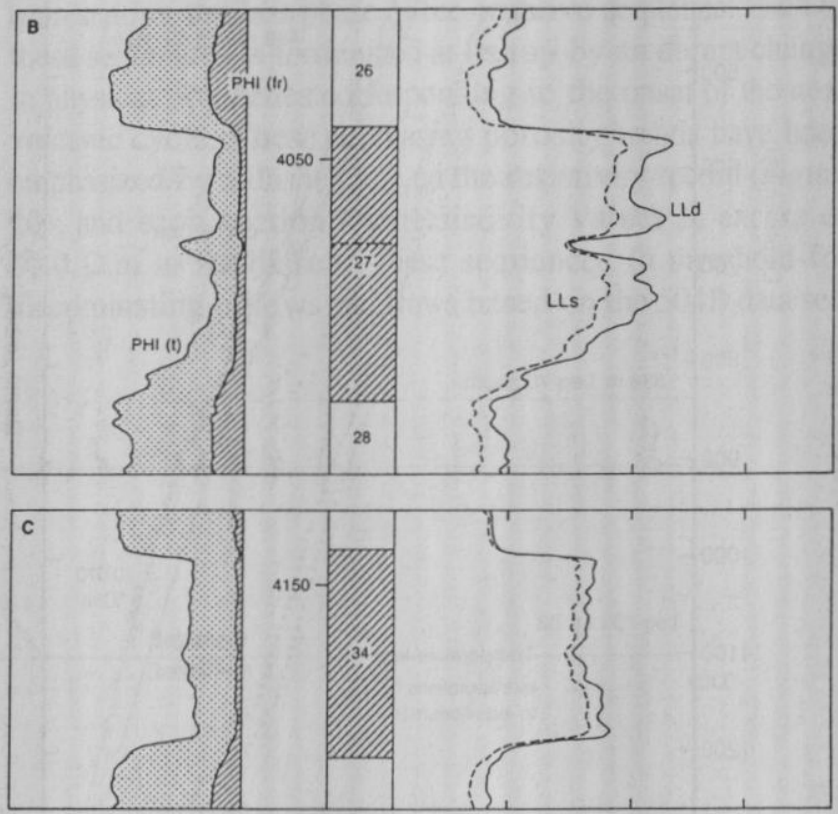

Fig. 18. Examples of resitivity patterns obtained for the massive units of layers $2 \mathrm{~A}$ and $2 \mathrm{~B}$ in hole 504B. (a) Unit $2 \mathrm{D}$, (b) unit 27 , and (c) unit 34 .

Layer $2 \mathrm{~A}$. Layer $2 \mathrm{~A}$ is characterized by the highest porosity in hole 504B (Figure 16). These high porosity values are related to the presence of horizontal fractures [Newmark et al., 1985; Pezard and Anderson, 1989] down to $3880 \mathrm{~m}$ (406 mbsf), below which a regime of mainly

This morphological feature is the barrier between two vertical fractures is observed. The presence of this boundary distinct hydrological regimes in the vicinity of the drillhole. fits with previous definitions of the limit between layer $2 \mathrm{~A}$ The abrupt transition from oxidative seawater alteration and layer 2B in hole 504B [CRRUST, 1982; Anderson et (UPAZ) to a reducing environment (LPAZ) calls in fact for a al., 1985b; Newmark et al., 1985], and the original permeability barrier of significant lateral extend. In a similar concept of a fractured, low-velocity layer $2 \mathrm{~A}$ [Houtz and way, the transition from suboxic alteration facies (Figure 5; Ewing, 1976; Francheteau, 1983]. These upper $130 \mathrm{~m}$ of LPAZ) to greenschist facies (GFAZ) is located at $4372 \mathrm{~m}$ the basaltic basement have the largest porosities of the entire (898 mbsf) [Emmermann, 1985; Alt et al., 1985, 1986; hole, with an average of $7.0 \%$ in the pillows (Figure 16). Laverne, 1987], or $4364 \mathrm{~m}$ ( $889 \mathrm{mbsf}$ ) [Adamson, The section of most intense fracturing observed within layer personal communication], where a pair of low-porosity units $2 \mathrm{~A}$ is bounded on top by unit 2D (from 3785 to $3799 \mathrm{~m}$; of intrusive origin is located (DSDP units 57 and 61). These 311 to $325 \mathrm{mbsf}$; Figure 18a), a 14-m-thick massive flow.

two units appear to cap the stockwork-like section

The set of temperature profiles recorded during successive discovered during leg 83 of DSDP [Anderson, et al., scientific legs in hole 504B (Figure 19a) shows that the $1985 a$ ], which emphasizes the strong morphological bottom of unit $2 \mathrm{D}$ defines the depth at which the control on hydrothermal alteration. The following discussion temperature increased rapidly (during DSDP legs 70 and 83), is guided by this mineralogical zonation. as the ocean water enters the underpressured aquifer 
A

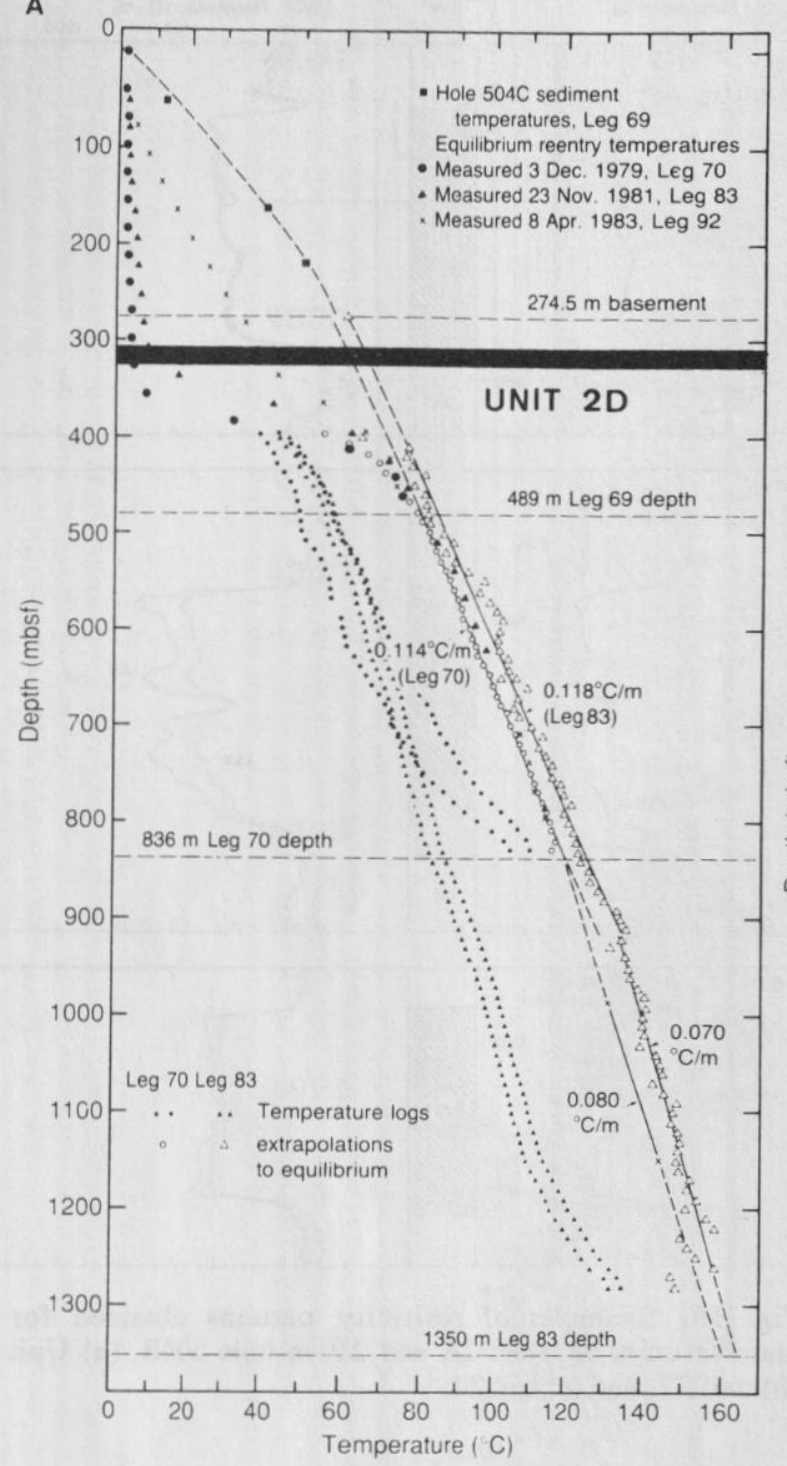

B

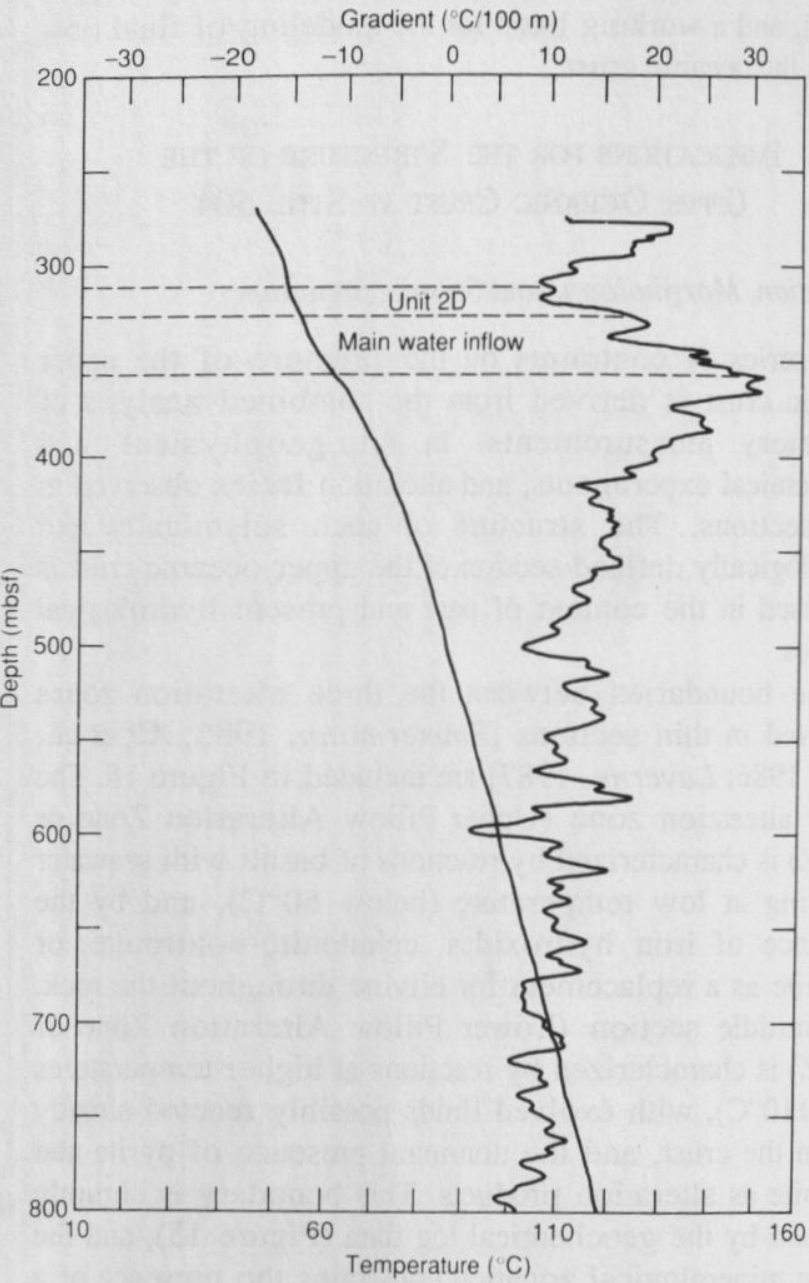

C

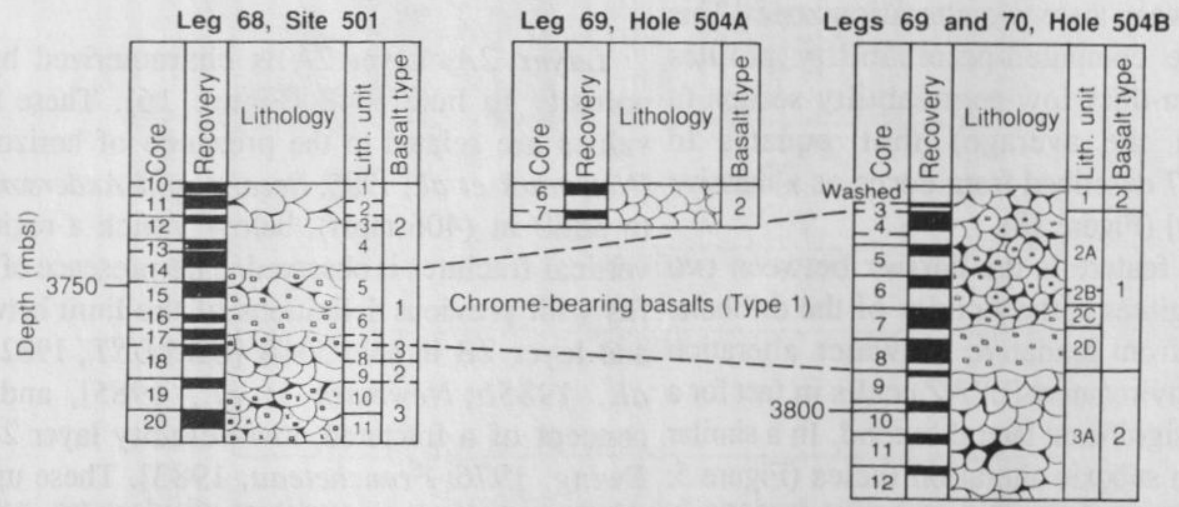

Fig. 19. (a) Temperature logs recorded in hole 504B during leg 69, 70, 83, and 92 [after Becker et al., 1989]; (b) Temperature log and thermal gradient recorded during leg 111, with the location of unit 2D [after Gable et al., 1989]; (c) Comparison of lithologies in holes 501, 504A, and 504B.

[Anderson and Zoback, 1982; Anderson et al., 1985c]. suggests that the main interval of water inflow is 30-mThis defines the upper limit of the main zone of water thick, which equates to the section of highest computed intake into the crust, although thinner permeable zones porosity and permeability in the hole (Figures 16 and 17). might be located above unit 2D (Figures 16 and 17). The This relationship has several possible implications, temperature gradient recorded during leg 111 (Figure 19b) suggesting for example that the structure allowing the 
under-pressured aquifer to develop was created near the ridge excellent point of comparison with hole 504B. The drill axis, where unit 2D was emplaced. This under-pressured hole penetrated $93 \mathrm{~m}$ of sediments and $571 \mathrm{~m}$ of $7.3 \mathrm{Ma}$ zone located in this high permeability conduit is thought to basaltic basement [Melson and Rabinowitz, 1979] (Figure have appeared during sealing of the upper part of the crust, 20). The sequences of increasing electrical resistivity with in relation to the diagenesis of diatom oozes into chert depth were interpreted as magma cycles [Hyndman and [Hobart et al., 1985]. Another explanation arises if Salisbury, 1983] (Figure 20), each representing a single hydrothermal waters already circulated through the crust were eruptive event at the ridge axis.

trapped at shallow depth below such thick units, close to the ridge axis.

Similar borehole inflows have been encountered in other deep-sea drill holes, although never studied as extensively as resis hole 504B. A kilometer away from 504B, hole 501 representing the last phase of the eruptive sequence. Each of penetrated $73 \mathrm{~m}$ into the basement. Two massive flows, these sequences is terminated at its top by an abrupt change comparable in size to unit $2 \mathrm{D}$ in hole 504B, were drilled in physical properties corresponding to the onset of the next through half way into the hole (Figure 19c). In situ volcanic cycle. These decreasing porosity trends have been temperature measurements also indicated the presence of a emphasized by a dashed line on the resistivity record (Figure downward flow of seawater in a zone located below a 20), and each section with resistivity values in excess of massive unit [Cann, al., 1983] (Figure 19c). DSDP hole $30.0 \Omega$.m at the base of these sequences (a threshold for $395 \mathrm{~A}$ is located in the North Atlantic and provides an discriminating pillows and flows based on the 504B data set)
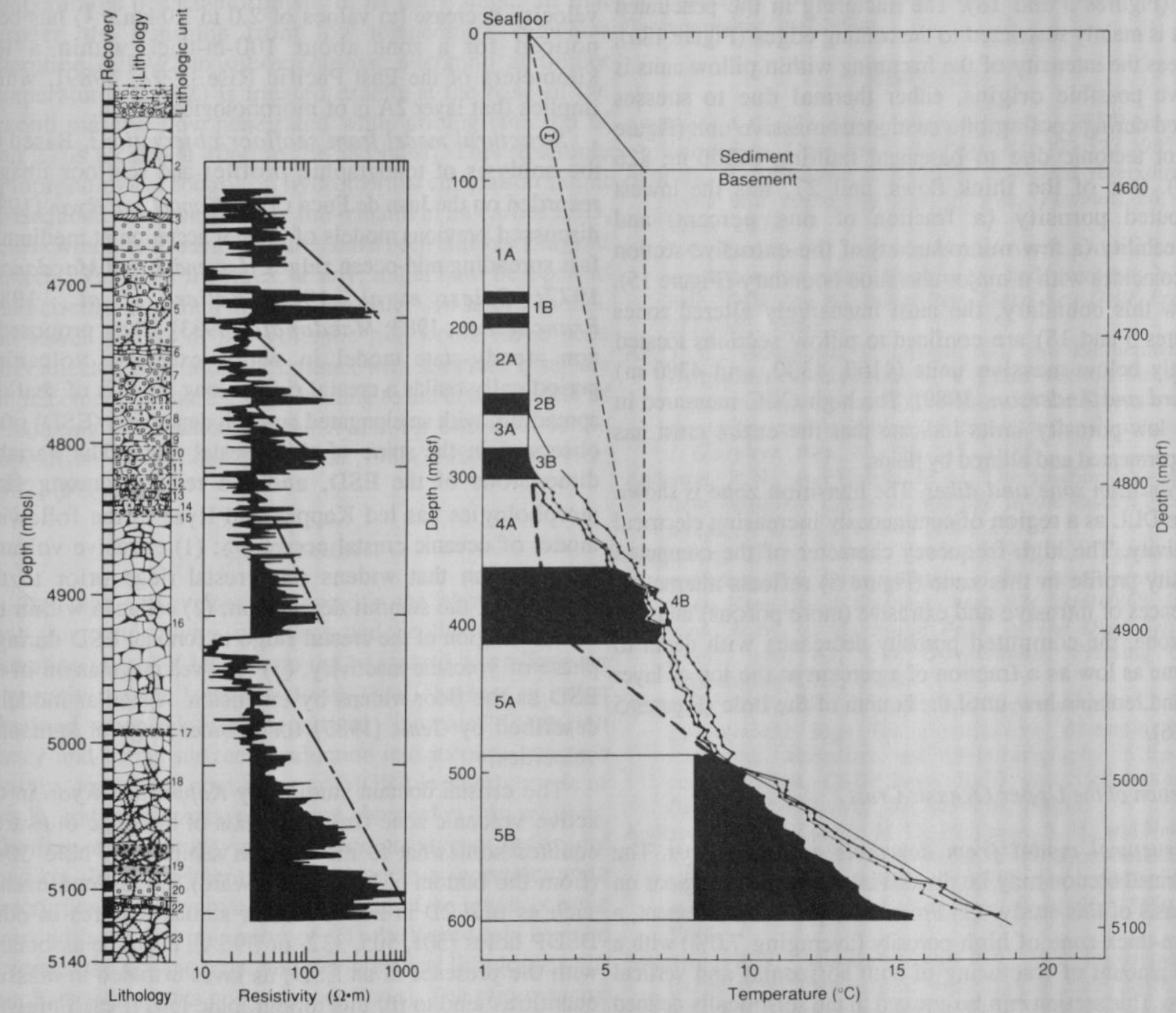

Fig. 20. Lithology from core description, electrical resistivity log, and temperature logs recorded in hole $395 \mathrm{~A}$ during leg $78 \mathrm{~A}$. The dashed lines represent the interpreted magmatic cycles of Hyndman and Salisbury [1983]. The shaded areas represent the sections of the crust with in situ resistivities measured in excess of $30.0 \Omega$.m. 
has been indicated on the temperature record with a dark begins approximatly at $4280 \mathrm{~m}$ (806 mbsf) and terminates shading. The downward flow of seawater, as indicated on the gradually in the dikes at about $4620 \mathrm{~m}$ (1146 mbsf), where successive temperature logs recorded during legs 45 and 78B, the porosity is as small as a fraction of one percent [Pezard appears to enter the basement below the base of the and Anderson, 1989].

previously defined massive units (referred to as $3 \mathrm{~A}$ and $4 \mathrm{~A}$ on Figure 20). The temperature log recorded during leg 109 of ODP has provided an evidence for seawater flow into unit 5A (Figure 20) [Kopietz et al., 1989]. These successive observations suggest the presence of several underpressured aquifers located at different depths in hole $395 \mathrm{~A}$, as opposed to the single inflow zone found in hole 504B below unit 2D. Such a structural and hydrologic contrast emphasizes the differences in the morphology of the basaltic basement between two plates accreted at different spreading rates.

Layer $2 B$. The discriminative analysis of in situ resistivity data performed on board ship (Figure 5) outlines the dominant presence of vertical fractures from the top of layer 2B ( $3880 \mathrm{~m}$, or $405 \mathrm{mbsf}$ ) to the bottom of the drill hole [Pezard and Anderson, 1989]. The low values of "apparent" porosities in massive units provide a means to discriminate the flows and sills from the more porous pillow units (Figures 5 and 18). The fracturing in the penetrated flows is mainly restricted to the cooling edges (Figure 18a), whereas the intensity of the fracturing within pillow units is of two possible origins, either thermal due to stresses applied during cooling of a contiguous massive unit (Figure 18 ), or tectonic due to basement faulting ( $4300 \mathrm{~m} ; 826$ mbsf). One of the thick flows, unit 27 , has the lowest computed porosity (a fraction of one percent) and permeability (a few microdarcies) of the extrusive section and coincides with a major alteration boundary (Figure 15). Below this boundary, the most intensively altered zones (Figures 5 and 15) are confined to pillow sections located directly below massive units $(4160,4330$, and $4380 \mathrm{~m})$ [Pezard and Anderson, 1989]. The high CEC measured in these low-porosity units indicate that the entire crust has been permeated and altered by fluids.

Transition zone and dikes. The transition zone is shown on the DLL as a region of continuously increasing electrical resistivity. The high-frequency character of the computed porosity profile in this zone (Figure 5) reflects alternating sequences of intrusive and extrusive (more porous) units. In this zone, the computed porosity decreases with depth to become as low as a fraction of a percent at the top of layer $2 \mathrm{C}$, and remains low until the bottom of the hole (Figures 5 and 16).

\section{Accretion of the Upper Oceanic Crust}

Structural model from downhole measurements. The penetrated section may be divided into three main regions on the basis of this study. (1) From the top of the basement, a 130 -m-thick zone of high porosity (averaging $7.0 \%$ ) with a large amount of fracturing of both horizontal and vertical nature. This section can be equated to the seismically defined layer 2A. (2) Below, a 500-m-thick zone of lower porosity consist of flows and pillows, and is equivalent to layer $2 \mathrm{~B}$. (3) The transition zone from layer $2 B$ to the sheeted dikes

The transition from dikes to pillows and flows is largely documented in ophiolite studies [Gass and Smewing, 1973; Kidd, 1977], and the contrast between the intrusive and the extrusive origin of these basalts is widely accepted as being related to the way new oceanic crust is formed at mid-ocean ridges. On the other hand, the relation to the large scale structure of the crust of the mineralized stockwork in the transition zone (4380-4400 m or $905-925 \mathrm{mbsf}$ ) is not yet understood. It has been proposed that the location of this hydrological feature is related to the mixing of cold, downgoing seawater with hot, already reacted fluids coming from the underlying dike section [Anderson et al., 1985a; Laverne, 1987]. Similarly, no definite explanation has been given for the existence of the "seismically slow" layer $2 \mathrm{~A}$, as opposed to an acoustically faster layer $2 \mathrm{~B}$. It has sometimes been related to a zone of intense alteration of the crust [Donelly et al., 1979; Salisbury et al., 1980]. Such a velocity decrease (to values of 2.0 to $3.0 \mathrm{~km} . \mathrm{s}^{-1}$ ) has been noticed for a zone about 100 -m-thick within a few kilometers of the East Pacific Rise [Vera, 1989], which implies that layer $2 \mathrm{~A}$ is of morphological origin.

Structural model from seafloor observations. Based on the analysis of topographic profiles and seafloor images recorded on the Juan de Fuca ridge, Kappel and Ryan [1986] discussed previous models of crustal accretion at medium to fast spreading mid-ocean ridges [Luyendyk and Macdonald, 1977; Spiess et al., 1980; Ballard et al., 1981; Francheteau, 1983; Macdonald, 1983]. They proposed a non steady-state model in which excessive volcanism periodically builds a crestal ridge along the axis of seafloor spreading, with an elongated summit depression (ESD) often observed in the spine of this crestal ridge. The variable dimensions of the ESD, and the relation among flow morphologies has led Kappel and Ryan to the following model of oceanic crustal accretion : (1) extrusive volcanic construction that widens the crestal ridge prior to the collapse of the summit depression, (2) collapse within the summit region of the crestal ridge to form an ESD during a phase of volcanic inactivity, (3) renewed magmatism in the ESD as the floor widens by extension. A similar model is described by Gente [1987] for a wider range of spreading velocities.

The crustal domain studied by Kappel and Ryan in the active volcanic zone (from the axis of the ridge outward), equates somewhat to the section sampled by hole 504B (from the bottom of layer 2B upward). Large flood events, such as unit 2D in hole 504B or similar features in other DSDP holes (501, 505, 332, or 395A), might be associated with the presence of an ESD, as lavas extruded in massive quantities tend to fill this topographic low. If each massive flow found at shallow depth in the oceanic crust is associated with an ESD, it is located in vertical cross section on top of a "volcanic construction" emplaced just before the collapse 
of the ESD. Lava morphologies have been found to be The comparison of the alteration-corrected porosity dependent on temperature, viscosity, phenocryst content, or profile to the alteration facies observed in thin sections and spreading rate at eruption [Bonatti and Harrisson, 1988], to the geophysical and geochemical logs suggests a strong evolving from sheet flow to pillow lava with time, as a correlation between alteration and morphology. The lateral volcanic construction develops and the crustal magma source continuity of morphological features such as layer $2 \mathrm{~A}$ or weakens. The crustal section located below the massive unit hydrological processes such as the underpressured aquifer emplaced into the ESD should consequently be constituted might be checked in the future with a series of closelymainly in its upper part of fractured pillows and lava tubes spaced holes drilled perpendicular to the ridge axis. The [Hekinian, 1984]. These weak structures are excellent resistivity-derived permeability profile reproduces in situ candidates, after collapsing into the ESD and being capped values obtained from packer experiments, which provides a by a 10 -m-thick flow (such as unit 2D or 27), to create the key to the low-permeability high-"apparent"-porosity highly porous and heterogeneous structures found in hole paradox obtained in the past from in situ experiments 504B [Anderson et al., 1985b]. This model implies that conducted in hole 504B.

layer $2 \mathrm{~A}$ might not be continuous away from the ridge axis and therefore laterally limited, as constrained by the progressive decrease in flow-rate observed since initial drilling of hole 504B.

In addition, it implies that hydrothermal fluids might be trapped below such impermeable massive units very close to the ridge crest. An associated alteration signature would therefore exist from the axis onward, allowing for high temperatures of metamorphism at an early stage. In that respect, the transition from low temperature seawater alteration (UPAZ) to suboxic/anoxic alteration at higher temperatures (LPAZ) is located exactly at the base of the second massive flow penetrated while drilling (the top of unit 27 is located at $4060 \mathrm{~m}$, or $585 \mathrm{mbsf}$ ). This example of morphological control on hydrothermal circulation might consequently be thought of as the remains of an earlier ESD, below which horizontal fractures have been entirely plugged on-axis. Very few fractures, if any, might now be open to fluid circulation within this "paleoaquifer". In such a model, the lower section of the volcanic pile would have been disconnected from a direct contact with seawater after the emplacement of unit 27 , thus leading to the development of a reducing environment below it and, for example, to the deposition of sulfides [Alt et al.,1985, 1986; Laverne, 1987] (Figure 15).

\section{CONCLUSIONS}

The high CEC values measured in the laboratory show that the conductivity of clays and zeolites present as alteration phases of MORB cannot be ignored when deriving a porosity profile from resistivity data. The low $m$ value obtained when relating porosity to "intrinsic" formation factor and taking surface conduction into account suggests that the conducting pore space of MORB is mainly made of cracks and microcracks, elsewhere observed in thin sections. The free-water porosity profiles computed from resistivity logs on this experimental basis lead to a more accurate description of the hydrological structure of the upper oceanic crust with the discrimination of (1) the large-scale seismic layers of the oceanic crust and (2) individual lithologic units (such as pillow units and massive flows). The two massive flows of lithologic unit $2 \mathrm{D}$ (penetrated at about $50 \mathrm{~m}$ into the basement) may be associated with the high-porosity, 30$\mathrm{m}$-thick underpressured aquifer located below.
Acknowledgements. The author is indebted to Keir Becker, Gary Olhoeft, and Peter Jackson for their thoughtful and thorough reviews of this manuscript. The laboratory measurements were made in the rock physics laboratory of Schlumberger in Ridgefield, Connecticut, thanks to the support of Ken Winkler, James Howard, and Larry McGowan. This manuscript benefited from informal discussions with Jeffrey Alt, Roger Anderson, Cristina Broglia, Michael Lovell, Dan Moos, Bill Ryan, and Ray Wilkens. This work was supported by the National Science Foundation through the Joint Oceanographic Institution.

\section{REFERENCES}

Adamson, A.C., Basement lithostratigraphy, DSDP hole 504B, Initial Rep. Deep Sea Drill. Proj., 83, 121-127 1985.

Aguilera, R., Analysis of naturally fractured reservoirs from sonic and resistivity logs, J. Pet. Technol., 26, 12331238, 1974.

Alt, J. C., Laverne, C., and Muehlenbachs, K., Alteration of the upper oceanic crust: Minerology and processes in DSDP hole 504B, leg 83, Initial Rep. Deep Sea Drill. Proj., 83, 217-248, 1985.

Alt, J. C., Honnorez, J., Lavene, C., and Emmermann, R., Hydrothermal alteration of a $1-\mathrm{km}$ section through the upper oceanic crust, DSDP hole 504B: The mineralogy, chemistry and evolution of seawater-basalt interactions, J. Geophys. Res., 91, 309-335, 1986.

Anderson, R.N., and Hobart, M.A., The relation between heat flow, sediment thickness, and age in the eastern Pacific, $J$. Geophys. Res., 81, 1968-1989, 1976.

Anderson, R.N., and Zoback, M.D., Permeability, underpressures, and convection in the oceanic crust near the Costa Rica rift, J. Geophys. Res., 87, 2860-2868, 1982.

Anderson, R.N., et al., Initial Rept. of the Deep Sea Drill. Proj., vol. 83, U.S. Government Printing Office, Washington D.C., $1985 a$.

Anderson, R.N., O'Malley, H., and Newmark, R. L., Use of geophysical logs for quantitative determination of fracturing, alteration, and lithostratigraphy in the upper oceanic crust, DSDP holes 504B and 556, Initial Rep. Deep Sea Drill. Proj., 83, 443-478, $1985 b$.

Anderson, R. N., Zoback, M. D., Hickman, S. H., and Newmark, R. L., Permeability versus depth in the upper oceanic crust: In situ measurements in DSDP hole 504B, eastern equatorial Pacific, J. Geophys. Res., 90, 3659-3669, $1985 c$.

Anderson, R.N., Malpas, J., and Alt, J.C., Integrated mass fluxes from geochemical well-logs in hole 504B, Costa Rica Rift, eastern equatorial Pacific, in Proceedings of ODP, Scientific Results, vol. 111, pp. 119-132, Becker, K., et al., Ocean Drilling Program, College Station, Tex., 1989. 
Archie, G.E., The electrical resistivity $\log$ as an aid in determining some reservoir characteristics, J. Pet. Technol., 5, 1-8, 1942.

ARCYANA, Transform fault and rift valley from bathyscaphe and diving saucer, Science, 190 (4210), 108-116, 1975. Ballard, R.D., Bryan, W.B., Heirtzler, J.R., Keller, G., Moore,
J.G., and van Andel, T.H., Manned submersible observations in the FAMOUS area: Mid-Atlantic Ridge, Science, 190 (4210), 103-108, 1975.

Becker, K., Large-scale electrical resistivity and bulk porosity of the oceanic crust, DSDP hole 504B, Costa Rica Rift, Initial Rep. Deep Sea Drill. Proj., 83, 419-427, 1985.

Becker, K., Permeability measurements in hole 504B, in Proceedings of ODP, Scientific Results, vol. 111, Becker, K., et al., pp. 317-325, Ocean Drilling Program, College Station, Tex., 1989.

Becker, K., et al., Drilling deep into young oceanic crust, hole 504B, Costa Rica Rift, Rev. Geophys., 27 (1), 79-102, 1989.

Bonatti, E., and Harrisson, C.G.A., Eruption styles of basalt in oceanic spreading ridges and seamounts: Effect of magma temperature and viscosity, J. Geophys. Res., 93, 2967. 2980, 1988.

Brace, W.F., Resistivity of saturated crustal rocks to $40 \mathrm{~km}$ based on laboratory studies, edited by J.G. Heacock, The Structure and Physical Properties of the Earth's Crust, Geophys. Monogr. Ser., vol. 14, 243-255, AGU, Washington D.C., 1971.

Brace, W.F., Permeability from resistivity and pore shape, $J$. Geophys. Res., 82, 3343-3349, 1977.

Brace, W.F., Permeability of crystalline rocks: New in situ measurements, J. Geophys. Res., 89, 4327-4330, 1984.

Brace, W.F., Orange, A.S., and Madden, T.R., The effect of pressure on the electrical resistivity of water-saturated crystalline rocks, J. Geophys. Res., 70, 5669-5678, 1965.

Brace, W.F., and Orange, A.S., Further studies of the effect of pressure on the electrical resistivity of rocks, J. Geophys. Res., 73, 5407-5420, 1968a.

Brace, W.F., and Orange, A.S., Electrical resistivity changes in saturated rocks during fracture and frictional sliding, $J$. Geophys. Res., 73, 1433-1445, 1968 b.

Broglia, C., and Moos, D., In situ structure and properties of $110 \mathrm{Ma}$ crust from geophysical logs in DSDP hole 418A, in Proceedings of ODP, Scientific Results, vol. 102, Salisbury, M.H., et al., pp. 29-47, Ocean Drilling Program, College Station, Tex., 1988.

Cann, J.R., et al., Initial Reports of the Deep Sea Drilling Project, vol. 69, U.S. Government Printing Office, Washington D.C., 1983.

Carman, P.C., Flow of Gases Through Porous Media, Academic, San Diego, California, 1956.

Clavier, C., Coates, G., and Dumanoir, J., The theoretical and experimental bases for the dual-water model for the interpretation of shaly sands, paper presented at the SPE 52nd Annual Fall Technical Conference, paper 6859, Soc. Pet. Eng., Denver, Co., 1977.

Corliss, J.B., et al., Submarine thermal springs on the Galapagos Rift, Science, 203, 1073-1083, 1979.

Costa Rica Rift United Scientific Team (CRRUST), Geothermal regimes of the Costa Rica rift, east Pacific, investigated by drilling, DSDP-IPOD legs 68, 69, and 70, Geol. Soc. Am. Bull., 93, 862-87, 1982.

Cox, C.S., The electrical conductivity of the oceanic lithosphere, edited by J.G. Heacock, in The Structure and Physical Properties of the Earth's Crust, Geophys. Monogr. Ser., vol. 14, pp.227-234, AGU, Washington D.C., 1971.

Cox, C.S., Constable, S.C., Chave, A.D., and Webb, S.C.,
Controlled-source electromagnetic sounding of the oceanic lithosphere, Nature, 320, 53-54, 1986.

Donnelly, T., et al., Initial Rep. of the Deep Sea Drilling Project, vol. 51, 52, and 53, U.S. Government Printing Office, Washington D.C., 1979.

Drury, M.J., and Hyndman, R.D., The electrical resistivity of oceanic basalts, J. Geophys. Res., 84, 4537-4546, 1979.

Edmond, J.M., Measures, C., McDuff, R.E., Chan, L.H. Collier, R., and Grant, B., Ridge crest hydrothermal activity and the balances of the major and minor elements in the ocean, Earth Planet. Sci. Lett., 46, 1-18, 1979.

Ellis, D.V., Well Logging for Earth Scientists, Elsevier, New York, 1987.

mmermann, R., Basement geochemistry, hole 504B, Init. Rep. Deep Sea Drill. Proj., 83 , 183-199, 1985.

Fehn, U., Green, K.E., Von Herzen, R.P., and Cathles, L.M., Numerical models for hydrothermal fields at the Galapagos spreading center, J. Geophys. Res., 88, 1033-1048, 1983.

Flovenz, O.G., Georgsson, L.S., and Arnason K., Resistivity structure of the upper crust in Iceland, J. Geophys. Res., 90, 10136-10150, 1985.

Francheteau, J., The oceanic crust, Scien. Am., 249, 114-129, 1983.

Francis, T.J., Large-scale resistivity experiment at DSDP hole 495B, Init. Rep. Deep Sea Drill. Proj., 60, 841-852, 1982.

Gable, R., Morin, R.H., and Becker, K., The geothermal state of hole 504B: ODP leg 111 overview, in Proc. ODP, Scientific Results, vol. 111, Becker, K., et al., pp. 87-96, Ocean Drilling Program, College Station, Tex., 1989.

Gass, I.G., and Smewing, J.D., Intrusion, extrusion, and metamorphism at constructive margins: Evidence from the Troodos massif, Cyprus, Nature, 242, 26-29, 1973.

Gente, P., Etude morphostructurale comparative de dorsales océaniques à taux d'expansion variés, in thèse de doctorat, Univ. de Bretagne Occidentale, Brest, France, 1987.

Haymon, R.M., and Koski, R.A., A 3-D model of along-axis hydrothermal circulation, discharge, and mineralization in the Bayda hydrothermal system, Northern Oman ophiolite, EOS, Trans. Am. Geophys. Union, 68, 1545, 1987.

Hekinian, R., Undersea volcanoes, Scien. Am., 251, 46-55, 1984.

Hermance, J.F., The electrical conductivity of materials containing partial melt: A simple model from Archie's law, Geophys. Res. Lett., 6, 613-616, 1979.

Herron, M., Subsurface geochemistry: Future applications of geochemical data, paper presented at Consultant's Meeting on Nuclear Data for Applied Nuclear Geophysics, IAEA, Vienna, Austria, 1986.

Hickman, S.H., Langseth, M.G., and Svitek, J.F., In situ permeability and pore pressure measurements near the MidAtlantic Ridge, DSDP hole 395A, Init. Rep. Deep Sea Drill. Proj., 78B, 699-708, 1984.

Hill, H.J., and Milburn, J.D., Effect of clay and water salinity on the electrochemical behavior of reservoir rocks, Trans. Am. Inst. Min. Metall. Pet. Eng., 207, 65-72, 1956.

Hobart, M.A., Langseth, M.G., and Anderson, R.N., A geophysical and geothermal survey on the south flank of the Costa Rica rift: sites 504 and 505, Init. Rept. Deep Sea Drill. Proj., 83, 379-404, 1985.

Houtz, R., and Ewing, J., Upper crustal structure as a function of plate age, J. Geophys. Res., 81, 2490-2498, 1976.

Hubbert, M.K., Darcy's law and the field equation of the flow of undeground fluids, Trans. Am. Inst. Min. Metall. Pet. Eng., 207, 222-239, 1956.

Hyndman, R.D., and Drury, M.J., The physical properties of oceanic basement rocks from deep drilling on the Mid- 
Atlantic Ridge, J. Geophys. Res., 81, 4042-4052, 1976.

Hyndman, R.D., and Salisbury, M.H., The physical nature of the oceanic crust on the Mid-Atlantic Ridge, DSDP hole 395A, Init. Rept. Deep Sea Drill. Proj., 78B, 839-848, 1983.

Jackson, P.D., Taylor-Smith, D., and Stanford, P.N., Resistivity-porosity-particle shape relationships for marine sands, Geophysics, 43, 1250-1268, 1978.

Johnson, D.L., and Schwartz, L.M., Unified theory of geometrical effects in transport properties of porous media, Trans. SPWLA, Annu. Logging Symposium, 30th, paper E, 1989.

Kappel, E.S., and Ryan, W.B.F., Volcanic episodicity and a non-steady state rift valley along northeast Pacific spreading centers: Evidence from Sea MARC I, $J$. Geophys. Res., 91, 925-940, 1986.

Karato, S.I., Physical properties of basalts from the Galapagos, leg 70, Init. Rep. Deep Sea Drill. Proj., 69, 423-428, 1985 .

Katsube, T.J., and Hume, J.P., Permeability determination in crystalline rocks by standard geophysical logs, Geophysics, 52, 342-352, 1987.

Keller, G.V., and Frischknecht, F.C., Electrical Methods in Geophysical Prospecting, Pergamon, New York, 1966.

Kempton, P.D., An interpretation of contrasting nucleation and growth histories from the petrographic analysis of pillow and dike chilled margins, hole 504B, DSDP leg 83, Init. Rep. Deep Sea Drill. Proj., 83, 165-181, 1985.

Kidd, R.G.W., A model for the process of formation of the upper oceanic crust, Geophys. J. R. Astron. Soc., 50, 149-183, 1977.

Kirkpatrick, R.J., The physical state of the oceanic crust: Results of downhole geophysical logging in the MidAtlantic Ridge at $23^{\circ} \mathrm{N}, \mathrm{J}$. Geophys. Res., 84, 178-188, 1979.

Kopietz, J., Becker, K., and Hamano, Y., Temperature measurements at site 395, ODP leg 109, in Proceedings of ODP, Scientific Results, vol. 109, Bryan, W.B., et al., pp.197-203, Ocean Drilling Program, College Station, Tex., 1989

Laverne, C., Les interactions basalte-fluide en domaine océanique. Minéralogie, pétrologie et géochimie d'un système hydrothermal: Le puits 504B, Pacific Oriental, thèse d'etat, Univ. de Marseille, 1987.

Lister, C.R.B., On the thermal balance of a mid-ocean ridge, Geophys. J. R. Astron. Soc., 26, 515-535, 1972.

Lister, C.R.B., On the penetration of water into hot rock, Geophys. J. R. Astron. Soc., 39, 465-509, 1974.

Lonsdale, R., and Klitgord, K.D., Structure and tectonic history of the eastern Panama basin, Geol. Soc. Am. Bull., 89, 981-999, 1978.

Luyendyk, B.P., and Macdonald, K.C., Physiography and structure of the inner floor of the FAMOUS rift valley: observations with a deep-towed instrument package, Geol. Soc. Amer. Bull., 88, 648-663, 1977.

Macdonald, K.C., Crustal processes at spreading centers, Rev of Geophys., 21, 1441-1454, 1983.

Madden, T.R., Random networks and mixing laws, Geophysics, 41, 1104-1125, 1976.

Mathews, M., Salisbury, M.H., and Hyndman, R.D., Basement logging on the Mid-Atlantic Ridge, DSDP hole 395A, Init. Rep. Deep Sea Drill. Proj., 78B, 717-730, 1983.

Matijevic, E., Surface and Colloid Science, vol. 7, John Wiley, New York, 1974.

Melson, W.G., and Rabinowitz, P.D., Init. Rept. of the Deep Sea Drilling Project, vol. 45, U.S. Government Printing Office, Washington D.C., 1979.

Mottl, M.J., Anderson, R.N., Jenkins, R.N., and Lawrence, J.R., Chemistry of waters sampled from basaltic basement in DSDP holes 501, 504B, and 505B, Init. Rep. Deep Sea Drill. Proj., 69, 475-484, 1983.
Nehlig, P., and Juteau, T., Deep crustal seawater penetration and circulation at ocean ridges: Evidence from the Oman ophiolite, Mar. Geol., 84, 209-228, 1988.

Newmark, R.L., Anderson, R. N., Moos, D., and Zoback, M.D., Sonic and ultrasonic logging of hole 504B and its implications for the structure, porosity, and stress regime of the upper $1 \mathrm{~km}$ of the oceanic crust, Init. Rep. Deep Sea Drill. Proj., 83, 479-510, 1985.

Norton, D., and Knapp, R., Transport phenomena in hydrothermal systems: The nature of porosity, Am.J. Sci., 277, 913-936, 1977.

Olhoeft, G.R., Electrical properties of water-saturated basalts, preliminary results to $506^{\circ} \mathrm{K}\left(223^{\circ} \mathrm{C}\right)$, U.S. Geol. Surv. Open File Rep., 77 (688pp.), 1977.

Olhoeft, G.R., Electrical properties of rocks, edited by Touloukian, Y.S., Judd, W.R., and Roy, R.F., Physical Properties of Rocks and Minerals, 257-330, McGraw-Hill, New York, 1981.

Pape, H., and Worthington, P.F., A surface-structure model for the electrical conductivity of reservoir rocks, paper presented at the 8th European Form. Eval. Symposium, London, 1983.

Pape, H., Riepe, L., and Schopper, J.R., A pigeon-hole model for relating permeability to specific surface, Log Anal., 23 (1), 5-13, 1982. (Errata, Log Anal., 23 (2), 50, 1982.)

Pape, H., Riepe, L., and Schopper, J.R., Petrophysical detection of microfissures in granites, Trans. SPWLA, Annu. Log. Symposium, 26th, paper P, 1985.

Parkhomenko, E.I., Electrical Properties of Rocks, edited and translated by G.V. Keller, Plenum, New York, 1967.

Patterson, M.S., The equivalent channel model for permeability and resistivity in fluid-saturated rocks; A re-appraisal, Mech. of Mater., 2, 345-351, 1983.

Pezard, P.A., and Anderson, R.N., Morphology and alteration of the upper oceanic crust from in situ electrical experiments in DSDP hole 504B, Proceedings of ODP, Scientific Results, vol. 111, pp. 133-146, Becker, K., et al., Ocean Drilling Program, College Station, Tex., 1989.

Pezard, P.A., Howard, J.J., and Lovell, M.A., Clay conduction and pore structure of oceanic basalts from DSDP hole 504B, Proceedings of ODP, Scientific Results, vol. 111, pp. 97 108, Becker, K., et al., Ocean Drilling Program, College Station, Tex., 1989.

Rai, C.S., and Manghnani, M.H., The effect of saturant salinity and pressure on the electrical resistivity of Hawaiian basalts, Geophys. J. R. Astron. Soc., 65, 395-405, 1981.

Ridge, M.J., A combustion method for measuring the cation exchange capacity of clay minerals, Log Anal., 3, 6-11, 1983.

Rink, M., and Schopper, J.R., Interface conductivity and its implications to electric logging, Trans. SPWLA, Annu. Logging Symposium, 15th, paper J, 1974.

Salisbury, M.H., Donnelly, T.W., and Francheteau, J., Geophysical logging in DSDP hole 417D, Initial Rep. Deep Sea Drill. Proj., 51, 52, 53, 705-713, 1980.

Schwartz, L.M., and Kimminau, S., Analysis of electrical conduction in the grain consolidation model, Geophysics, $52,1402-1411,1987$.

Sclater, J.G., and Francheteau, J., The implication of terrestrial heat-flow observations on current tectonic and geochemical models of the crust and upper mantle of the Earth, Geophys. J. R. Astron. Soc., 20, 509-542, 1970.

Sen, P.N., Scala, C., and Cohen, M.H., A self-similar model for sedimentary rocks with applications to the dielectric constant of fused glass beads, Geophysics, 46, 781-795, 1981.

Serra, O., Fundamentals of Well-Log Interpretation, Elsevier, New York, 1984.

Shankland, T.J., Electrical conduction in rocks and minerals: 
Parameters for interpretation, Phys. of the Earth and Plan. Int., 10, 209-219, 1975.

Shankland, T.J., and Waff, H.S., Conductivity in fluid-bearin rocks, J. Geophys. Res., 79, 4863-4868, 1974.

Shankland, T.J., and Waff, H.S., Partial melting and electrical conductivity anomalies in the upper mantle, J. Geophys. Res., 82, 5409-5417, 1977.

Shipboard Scientific Party, Site 504, Proceedings of $O D P$, Initial Reports, vol. 111, Becker, K., et al., Ocean Drilling Program, College Station, Tex., 1988.

Simmons, G., and Richter, D., Microcracks in rocks, edited by Strens, R.G.J., The Physics and Chemistry of Minerals and Rocks, pp. 105-137, John Wiley, New York, 1974.

Sleep, N.H., and Wolery, T.J., Thermal and chemical constraints on venting of hydrothermal fluids at mid-ocean ridges, J. Geophys. Res., 83, 5913-5922, 1978.

Spiess, F.N., et al., East Pacific Rise: Hot springs and geophysical experiments, Science, 207, 1421-1432, 1980.

Snow, D.T., Rock fracture spacings, openings, and porosities, J. Soil Mech. Am. Soc. Civ. Eng., 94, 73-91, 1968.

Sundberg, K., Effect of impregnating waters on electrical conductivity of soils and rocks, Trans. of the Amer. Inst. of Mining and Metal. Eng., 79, 367-391, 1932.

Talibudeen, O., Cation exchange in soils, edited by Greenland, D.J., and Hayes, M.H.B, The Chemistry of Soil Processes, pp. 115-177, John Wiley, New York, 1981.

Towle, G., An analysis of the formation resistivity factorporosity relationship of some assumed pore geometries, Trans. SPWLA, Annu. Log. Symposium, 3rd, paper 3, 1962.

Ucok, H., Temperature dependence of the electrical resistivity of aqueous salt solutions and solution-saturated porous rocks, Ph.D. thesis, Univ. Southern Calif., Los Angeles, 1979.

Vera, E., The structure of 0 - to 0.2-M.Y.-old oceanic crust at $9^{\circ} \mathrm{N}$ on the East Pacific Rise from expanded spread profiles, in Ph.D. thesis, Columbia Univ., New York, 1989.

von Herzen R.P., Francis, T.J., and Becker, K., In situ largescale electrical resistivity of the ocean crust, hole 504B, Init. Rep. Deep Sea Drill. Proj., 69, 237-244, 1983.

Walsh, J.B., and Brace, W.F., The effect of pressure on porosity and the transport properties of rocks, J. Geophys. Res., $89,9425-9431,1984$.

Waff, H.S., Theoretical considerations of electrical conductivity in a partially molten mantle and implications for geothermometry, J. Geophys. Res., 79, 4003-4010, 1974.

ard, S.H., and Fraser, D.C., Conduction of electricity in rocks, edited by Musgrave, A.W, Mining Geophysics, vol. 2, pp.197-223, Society of Exploration. Geophysicists, Tulsa, Okla., 1967.

Waxman, M.H., and Smits, L.J.M., Electrical conductivities in oil-bearing shaly sands, Soc. Pet. Eng., 8, 107-122, 1968.

Wilkens, R., Schultz, D., and Carlson, R., Relationship of resistivity, velocity, and porosity for basalts from downhole well-logging measurements in hole 418A, edited by Salisbury, M.H., et al., Proceedings of $O D P$, Scientific Results, vol. 102, pp., 69-75, Ocean Drilling Program, College Station, Tex., 1989.

Williams, D.L., Von Herzen, R.P., Sclater, J.G., and Anderson, R.N., The Galapagos spreading centre: Lithospheric cooling and hydrothermal circulation, Geophys. J. R. Astron. Soc., 38, 587-608, 1974.

Winsauer, W.O., and McCardell, W.M., Ionic double-layer conductivity in reservoir rocks, Amer. Inst. of Mining and Metal. Eng., 198, 129-134, 1953.

Worthington, P., The evolution of shaly-sand concepts in reservoir evaluation, The Log Anal., Jan-Feb, 1985.

Wong, P.Z., The statistical physics of sedimentary rock. Physi. Today, December, 24-32, 1988.

Wyllie, R. J., Gregory, A. R., and Gardner, G. H. F., An experimental investigation of factors affecting elastic wave velocities in porous media, Geophysics, 23, 459. 469, 1958.

Yariv, S., and Cross, H., Geochemistry of Colloid Systems,. Springer-Verlag, New-York, 1979.

Young, P.D., and Cox, C.S., Electromagnetic active source sounding near the East Pacific Rise, Geoph. Res. Lett., vol. $8,10,1043-1046,1981$.

P.A. Pezard, Borehole Research Group, Lamont-Doherty Geological Observatory, Palisades, NY 10964.

(Received March 20, 1989;

revised November 22, 1989;

accepted November 24, 1989). 